\title{
1 People prefer coordinated punishment in cooperative interactions
}

2

3 Authors

4 Lucas Molleman ${ }^{1,2,3 *}$, Felix Kölle ${ }^{2,4^{*}}$, Chris Starmer ${ }^{2}$ and Simon Gächter ${ }^{2,5,6}$

5

6 Affiliations

$7{ }^{1}$ Center for Adaptive Rationality, Max Planck Institute for Human Development, Berlin,

8 Germany

$9{ }^{2}$ Centre for Decision Research and Experimental Economics, School of Economics,

10 University of Nottingham, United Kingdom

$11{ }^{3}$ Amsterdam Brain and Cognition Center, University of Amsterdam, The Netherlands

$12{ }^{4}$ Faculty of Management, Economics and Social Sciences, University of Cologne, Germany

$13{ }^{5}$ Center for Economic Studies, Munich, Germany

$14{ }^{6}$ IZA Institute of Labour Economics, Bonn, Germany

15

16 * Corresponding authors: Lucas Molleman (1.s.molleman@uva.nl; ORCID: 0000-0003-0184-

17 4240); Felix Kölle (felix.koelle@uni-koeln.de; ORCID: 0000-0003-4036-8566)

18

19 Keywords

20 cooperation, punishment, conditional preferences, coordination, decision-making experiment, 21 social dilemmas

23 Date

$24 \quad 15$ July 2019 


\section{Abstract}

26 Human groups can often maintain high levels of cooperation despite the threat of 27 exploitation by individuals who reap the benefits of cooperation without contributing to 28 its costs $^{1-4}$. Prominent theoretical models suggest that cooperation is particularly likely

29 to thrive if people join forces to curb free riding and punish their non-contributing peers

30 in a coordinated fashion ${ }^{5}$. However, it is unclear whether and, if so, how people actually 31 condition their punishment of peers on punishment behaviour by others. Here we 32 provide direct evidence that many people prefer coordinated punishment. With two 33 large-scale decision-making experiments (total $N=4,320$ ), we create minimal and 34 controlled conditions to examine preferences for conditional punishment and cleanly 35 identify how individuals' punishment decisions are impacted by punishment behaviour 36 by others. We find that the most frequent preference is to punish a peer only if another 37 (third) individual does so as well. Coordinated punishment is particularly common among participants who shy away from initiating punishment. With an additional experiment we further show that preferences for conditional punishment are unrelated to well-studied preferences for conditional cooperation. Our results highlight the importance of conditional preferences in both positive and negative reciprocity, and provide strong empirical support for theories that explain cooperation based on coordinated punishment. 
The ecological success of humans has often been attributed to our propensity for cooperation $^{2,4}$. Many people are willing to go out of their way to help others, allowing human groups to deal with environmental challenges and to do things no individual can achieve on their own. But, as natural as it might seem, cooperation looks puzzling from the viewpoint of rational self-interest: why would one cooperate if others can reap the benefits of cooperation without paying the costs? This supposed 'free rider problem' affects countless real-world situations, ranging from day-to-day work in teams and paying taxes to curbing overfishing and reducing carbon dioxide emissions. Moreover, a vast range of theoretical models and empirical studies from across the biological and social sciences have documented that, when studied in isolation, individually costly cooperation tends to break down through processes of natural selection or (social) learning, which often favour free riding ${ }^{1-9}$.

Peer punishment ${ }^{15-18}$ is one of the key mechanisms proposed to explain why cooperation can thrive despite free rider incentives. When individuals sanction their uncooperative interaction partners, relative gains from free riding can be offset ${ }^{19-21}$. Influential theoretical arguments suggest that punishment can be particularly effective in promoting cooperation when individuals punish non-cooperators in a coordinated fashion ${ }^{5}$. In this paper we use large-scale decision-making experiments to provide systematic empirical evidence for coordinated punishment in a social dilemma situation.

Peer punishment has been extensively studied in a wide range of different experimental settings, both in decision-making laboratories and in the field, as well as across different interaction settings and across cultures ${ }^{14,20-29}$. By and large, these studies indicate that many people are inclined to punish free riding interaction partners (often motivated by negative emotions such as anger), supporting the idea that such peer punishment can lead to a welfareenhancing stabilization of cooperation at high levels.

While in experimental settings punishment has great potential to support cooperation, evolutionary models suggest that punishment can only emerge under very limited circumstances $^{30-32}$. The reason is that punishment often entails costs for those who mete it out. This can create a 'second-order' free rider problem: while only some individuals incur the costs of punishing, all members of a group may benefit from enhanced cooperation after noncooperators are punished. Hence, from an individual perspective it can pay to refrain from 
punishment ${ }^{24,33-35}$. Over time, this may result in a decline of punishment in a population of self-interested agents, compromising its potential to support cooperation.

Theoretical and experimental studies have explored various mechanisms that may address the second-order free rider problem, such as reputational benefits for punishers ${ }^{36-39}$, the punishment of those who fail to punish ${ }^{40-43}$, commitment of resources to prepare joint sanctioning of free riders before cooperative interactions take place ${ }^{35,44,45}$, or the establishment of specialized authorities that monitor behaviour and punish free riders ${ }^{46-48}$. In these studies, individuals' decisions to punish are typically considered in frameworks allowing only independent and uncoordinated actions. In real life, however, punishment does not typically take place in a social vacuum. Like cooperation, punishment can often be made dependent on the behaviour of others ${ }^{40,49-51}$, and empirical evidence from the field suggests that such coordinated punishment may be common in human groups ${ }^{15,17,52-54}$. Moreover, an influential evolutionary model indicates that punishment is likely to emerge when individuals can coordinate their punishment ${ }^{5}$. This model suggests that the second-order free rider problem can be largely avoided when individuals make their punishment conditional upon the punishment decisions of others. 'Ganging up' against free riders likely decreases the costs for individual punishers (e.g., through reduced risks for retaliation), and may increase the impact and effectiveness of punishment as individuals join forces in meting it out ${ }^{2,5,17}$.

Despite these promising theoretical results, there is only scarce empirical support for the claim that individuals have a preference for coordinated punishment. While field evidence e $^{15,17,52-54}$ is consistent with the idea of coordinated punishment, it is not conclusive about whether people prefer coordinated punishment over independent punishment. Experimental evidence is needed to establish the existence of preferences for coordinated punishment. Hitherto, experimental studies of conditional punishment are rare, and mainly focus on how punishment is impacted by the distribution of cooperative behaviour (not the punishment behaviour) in the population, or analyse how aggregate levels of cooperation are affected when free riders can only be punished if multiple peers agree to do so ${ }^{14,49-56}$. Here, we investigate whether people prefer to coordinate their punishment in the context of an experiment in which individuals can explicitly condition their punishment on the punishment decisions of others. That is, we ask whether, analogously to conditional preferences observed in pro-social contexts like cooperation ( $c f$. positive reciprocity), such conditionality is also 
106 characteristic of preferences to punish others ( $c f$. negative reciprocity), and if so, whether positive and negative reciprocity are correlated.

108 Our results reveal that people do indeed tend to coordinate punishment with their peers. Among participants who are willing to punish in at least one instance, the most frequent preference is to use coordinated punishment: punishing only if others do so as well.

111 Alternative punishment preferences (punishing irrespective of what others do, and punishment

112 only if others do not) are observed much less frequently. Coordinated punishment particularly

113 predominates among participants who refrain from initiating punishment. Furthermore, we 114 confirm all these main results with a large-scale replication study. An analysis of participants' 115 self-reported motivations suggests that anger is an important driver of punishment, and that 116 coordinated punishment is associated with equality concerns towards the other punisher.

117 In a follow-up experiment, we demonstrate that preferences for conditional punishment are 118 unrelated to preferences for conditional cooperation. That is, while at the aggregate level we 119 observe that individuals are more likely to cooperate and punish if their peers do so too, at the 120 individual level there is no correlation between preferences for cooperation and punishment.

121 We conduct a decision-making experiment with $N=2,004$ participants. After reading 122 instructions and passing comprehension checks, participants are allocated to groups of three. 123 In their group, they play a one-shot game consisting of two stages. The first stage is a binary 124 linear public goods game (PGG) in which all individuals simultaneously choose to either 'defect' or to 'cooperate'. From the perspective of an individual participant, defecting yields a 126 personal benefit of 5 monetary units (MU), and $0 \mathrm{MU}$ for the other two group members.

127 Cooperating yields 2 MU for all three group members. This setup creates a social dilemma:

128 while average payoffs in a group are maximised when all members cooperate, individuals can 129 maximise their own monetary benefits by defecting (i.e. free riding), making defection a 130 dominant strategy leading to a socially inefficient outcome.

131 At the start of the second stage, two of the three group members are randomly allocated the 132 roles of Punishers, and the remaining one is allocated the role of Target who can be punished 133 but cannot punish the Punishers. The PGG decision of the Target is revealed, and then 134 Punishers make binary choices whether or not to punish (i.e. assign deduction points to) the 135 Target. Assigning deduction points incurs a cost of $1 \mathrm{MU}$ to the Punisher, and 3 MU to the 136 Target. The impact of punishment is additive: when a Target is punished by one group 
member they lose $3 \mathrm{MU}$ and when they are punished by both of their group mates they lose 6 MU. Punishers cannot assign deduction points to one another, neither can they observe each other's PGG decision when making their deduction point decision (mitigating possible effects of inequality between Punishers stemming from the contribution stage).

We examine whether people prefer to coordinate their punishment by having Punishers make two types of punishment decisions. First, they make an 'unconditional' punishment decision, deciding whether they want to punish the Target or not, irrespective of the decision of the other Punisher. Subsequently, they make two 'conditional' punishment decisions, in which Punishers can condition their punishment on that of the other Punisher. To do this, we use the strategy method ${ }^{63}$ : Punishers indicate whether or not they want to punish the Target in case the other Punisher chooses (1) to punish or (2) to not punish the Target. Our analysis mainly focuses on these two decisions made by the $N=1,336$ Punishers in our experiment. Figure 1 summarises the decision situations.

Once both Punishers have entered both types of decisions, one Punisher is randomly chosen and their unconditional punishment decision is implemented to initiate the punishment procedure. Subsequently, the corresponding conditional punishment decision of the other Punisher is implemented (Methods). This setup yields an incentive-compatible decision situation in a minimal social context that allows us to cleanly measure how people condition their punishment on the punishment decisions of others. Importantly, the strategy method yields a full punishment profile for each individual that is independent of their beliefs about other people's punishment decision. Because of the one-shot nature of the game, there are also no strategic incentives for punishment. Further, note that because punishment is costly and the game is played only once, if players are only interested in maximising their own material payoff, no one is predicted to punish. As a result, full defection with no-punishment is the only Nash equilibrium of the game.

In a post-experimental questionnaire we asked Punishers to self-report their experienced levels of anger when they learned about the Target's PGG decision (Methods). Negative emotions such as anger are commonly identified as key drivers of punishment ${ }^{21,27,64-67}$. With this questionnaire item we test whether anger is not only correlated with individual punishment decisions but also with preferences for conditional punishment. 
167 The cooperation rate in the PGG stage of the game was 48\%. Among the 1,336 Punishers, the overall unconditional punishment rate was $11.4 \%$. Unconditional punishment varied considerably with the cooperation decisions of Punishers and their Target. In particular, unconditional punishment rates were highest when the Punisher cooperated and the Target defected (24.0\%), and lowest when both the Punisher and Target cooperated (5.5\%). When the Target cooperated and the Punisher defected, punishment was also low (5.7\%), while if both players defected punishment was intermediate occurring in $10.0 \%$ of the cases.

On aggregate, people were much more likely to punish their peers when the other punisher did so as well. A decision of the other Punisher to punish the Target increased overall punishment rates by $40 \%$ (from $11.1 \%$ when others did not punish, to $15.5 \%$ when they did; McNemar test: $\left.\chi^{2}(1)=16.66, P<0.001, \varphi_{c}=0.11\right)$. We interpret this as evidence that people tend to prefer to coordinate their punishment.

To test the robustness of this result, we fitted a logistic generalized linear model to conditional punishment decisions, confirming that this increase is statistically significant (Table 1, Model $1, P<0.001)$. This model further shows that participants who punished unconditionally displayed much higher levels of punishment in the conditional stage ('Unconditional punishment'; $P<0.001)$. It also reveals that the relative influence of the other Punisher's punishment differs strongly between those who did and those who did not punish unconditionally. For those who did not punish unconditionally (the baseline case in Model 1), we observe a strong and positive effect of the other's punishment on punishment levels. By contrast, for those who did punish unconditionally, the analysis indicates that the decision of the other Punisher did not systematically affect their punishment (the joint effect of 'Other punishes' and its interaction term with 'Unconditional punishment' is not significantly different from zero; Wald test: $\left.\chi^{2}(1)=0.15, P=0.696\right)$. Taken together, this analysis suggests that coordination effects are driven by those who did not punish unconditionally.

In Model 2 we confirm that the positive effect of the other punisher's decision is robust to alternative model specifications, and further investigate how preferences for coordinated punishment vary with the Target's decision to cooperate or defect. We find that a Target's decision to cooperate leads to lower overall levels of punishment, as indicated by the significant negative 'Target cooperated' dummy. Preferences for coordinated punishment, however, seem independent of the Target's PGG decision as the interaction term of 'Target cooperated' $\times$ 'Other punishes' is not statistically significant. This means that defection leads 
to higher levels of punishment, but does not make it more likely that people coordinate (or anti-coordinate) their punishment. However, as unconditional punishment towards cooperators ("antisocial punishment") ${ }^{25}$ occurred only in $5.6 \%$ of cases (see above), coordinated antisocial punishment is very rare in our data; only $0.63 \%$ of the cooperators got punished in a coordinated way.

We now turn to the individual-level preferences for conditional punishment elicited with the strategy method (Figure 1e,f). We distinguish four 'punishment types': $(i)$ 'coordinated punisher', punishing only if the other does so as well; (ii) 'anti-coordinated punisher', punishing only if the other does not punish; (iii) 'independent punisher', punishing regardless of the other's punishment decision; and (iv) 'non-punisher', not punishing at all. Here we focus on the relative frequencies of these types.

In line with established findings for one-shot games without strategic incentives to punish $^{23,27,68,69}$, the majority of participants in the role of Punisher chose to never punish (78.9\%). Among the $N=282$ Punishers who punish at least once, we find a strong and

213 striking pattern (Figure 2a). In this group, coordinated punishers are most frequent (47.5\%).

214 The independent punishers and anti-coordinated punishers are much less frequent $(25.9 \%$ and $21526.6 \%$, respectively).

216 Figure 2 also shows the distribution of punishment types, split by the unconditional 217 punishment decision. In line with the regression results presented in Table 1, this

218 decomposition reveals that coordinated punishment is particularly prevalent among those who 219 do not punish in the unconditional stage (Figure 2b). Among those participants who do punish 220 in the unconditional punishment stage, we most frequently observe independent punishment

221 (Figure 2c). The distribution of punishment types across unconditional punishers and 222 unconditional non-punishers is highly significantly different $\left(\chi^{2}(2)=52.88, P<0.001, \varphi_{c}=\right.$ 223 0.43). In particular, among unconditional non-punishers there is a significantly larger fraction 224 of 'coordinated punishers' $\left(\chi^{2}(1)=37.77, P<0.001, \varphi_{c}=0.37\right)$ and a significantly smaller 225 fraction of 'independent punishers' $\left(\chi^{2}(1)=44.49, P<0.001, \varphi_{c}=0.40\right)$. The fraction of 'anti226 coordinated punishers', in contrast, is very similar across both subsets $\left(\chi^{2}(1)=0.11, P=\right.$ $2270.738, \varphi_{c}=0.02$; see Supplementary Figure 1 for a decomposition of conditional punishment 228 types for each of the outcomes of the PGG). 
These behavioural patterns demonstrate that many people prefer coordinated punishment. As we used a new experimental paradigm to examine rarely explored preferences for conditional punishment, one might ask how robust our results are, and, perhaps more fundamentally, why people would prefer coordinated punishment.

To test the robustness and replicability of our results, and to further probe motivations underlying conditional punishment preferences, we ran a new study with $N=2,316$ additional participants. The design and the procedures of this new study were the same as in our original experiment, with the following exceptions. First, to rule out that the observed patterns in punishment preferences are due to confusion about the strategy method and the payoff consequences for punishment, we added a set of control questions right before participants entered the punishment stages. Second, as a further robustness check we counterbalanced the order in which participants made their punishment decisions, such that in half of the groups, Punishers completed the 'conditional' stage ( $c f$. Figure 1d,e) before the 'unconditional' stage ( $c f$. Figure 1c). Third, to further explore the motivational factors underlying preferences for conditional punishment, we extended the post-experimental questionnaire with items probing not only experienced anger when making punishment decisions, but also other possible motivations such as a desire for revenge towards the Target, reciprocity towards the other Punisher, as well as inequality concerns (see below).

The results of the new study closely replicate our original findings. Again, participants were significantly more likely to punish when the other punisher did so as well (Supplementary Table 1), demonstrating that the observed punishment patterns in our original study were not driven by confusion. When we focus on the people who punish at least once in the conditional punishment stage and split up the data according to decisions in the unconditional punishment stage, we observe that the same punishment types predominate as before: coordinated punishment prevails among unconditional non-punishers $(55.3 \%)$ and independent punishment prevails among unconditional punishers (51.4\%; Supplementary Figure 2). As before, these distributions of conditional punishment preferences significantly differed from each other $\left(\chi^{2}(2)=37.01, P<0.001, \varphi_{c}=0.35\right)$. Furthermore, each of them closely match their corresponding distribution from our original study (unconditional non-punishers: $\chi^{2}(2)=$ 2.94, $P=0.230, \varphi_{c}=0.10$; unconditional punishers; $\chi^{2}(2)=1.07, P=0.584, \varphi_{c}=0.06$ ), and did not vary with order $\left(\chi^{2}(2)=1.61, P=0.448, \varphi_{c}=0.11\right.$ for unconditional non-punishers; $\chi^{2}(2)=2.63, P=0.268, \varphi_{c}=0.12$ for unconditional punishers $)$. 
261 Taking the data from both studies together, we find that among those $N=584$ participants 262 who punish at least once in the conditional stage, $43 \%$ have a preference for coordinated punishment. A further $32 \%$ are independent punishers and $25 \%$ are anti-coordinated punishers. So, overall, our results suggest that coordinated punishment is a strong and robust phenomenon prevailing across different outcomes of cooperative interactions. Preferences for coordinated punishment are particularly common among people who do not punish unconditionally. In the Supplementary Information, we develop a simple model to explore how the relative frequencies of punishment preferences observed in our data may impact the relative payoffs of cooperation and defection. This model suggests that the range of conditions for which cooperation is favoured over defection can be substantially enhanced by the presence of individuals who do not punish unconditionally, but who are prepared to punish once another individual initiates it (Supplementary Figure 3; Supplementary Results).

To understand the potential drivers and underlying motivations of individuals' punishment preferences, we analyse Punishers' reported levels of anger (using data from both studies) as well as their responses to the post-experimental questionnaire in our replication study. For eliciting anger levels, we asked punishers to rate their level of anger when making their punishment decisions on a 7-point scale (1: not angry at all; 7: very angry). On average, anger scores are highest when the Punisher cooperated and the Target defected (3.7) and lowest if both cooperated (1.5). We find anger levels to be significantly higher for unconditional punishers than for unconditional non-punishers (3.7 versus 2.2; Mann Whitney U (MWU)test, $z=15.34$, d.f. $=1, P<0.001, r=0.29$ ). (Figure 3). Participants who never punished report average anger levels of only 2.1, which is significantly lower than those reported by any of the other types (MWU-tests for pairwise comparisons, d.f. $=1$, all $P<0.001)$. Furthermore, independent punishers tend to report higher average anger levels (3.8) than coordinated punishers (3.1, MWU-test, $z=3.67$, d.f. $=$ 1, $P<0.001, r=0.18$ ) and anti-coordinated punishers (3.2, MWU-test, $z=2.86$, d.f. $=1, P=$ $0.004, r=0.16$ ), while there is no significant difference between the latter two types (MWUtest, $z=0.55$, d.f. $=1, P=0.586, r=0.03$ ). When accounting for multiple comparisons, differences that are significant in this analysis remain so (i.e., by multiplying $P$ values by 6 ; the number of comparisons). These findings suggest that conditional punishers may be less emotionally aroused than independent punishers, and are less driven by emotions of anger. 
In the extended questionnaire from the new study, participants used a 7-point scale to indicate

294 their agreement to a set of statements, designed to test a set of candidate motivations that we hypothesized to be associated with some specific punishment preferences but less so with others. Our approach was to perform targeted comparisons for each statement, singling out one specific punishment type which we linked, a priori, to the respective motivation. In particular, we tested whether agreement scores were higher in that punishment type than in others, giving us first correlational hints at possible motivations behind conditional punishment preferences.

301 In our analyses, we focus only on those participants who punished at least once in the 302 conditional stage. That is, we disregard the non-punishers - who, unsurprisingly, report different motivations for their behaviour in the punishment stage of the experiment, relative to those who punished at least once, rendering all overall tests between distributions of types significant (Kruskal-Wallis tests, d.f. $=3$, all $P<0.001$ ). For a full analysis of participants' responses broken down by punishment type, including non-punishers, see Supplementary Results.

Our analysis of anger outlined above suggests that independent punishers (IP) might be driven by a thirst for revenge ${ }^{70,71}$. This motivation is corroborated by the observation that independent punishers agree most with the statement 'I wanted to reduce the other player's earnings myself' $\left(\mu_{\mathrm{IP}}=4.8, \mu_{\text {other punishers }}=4.0\right.$; MWU-test: $z=4.11$, d.f. $=1, P<0.001, r=$ 0.24). By contrast, one motivation behind anti-coordinated punishment (ACP) could be wishing to see free riding being sanctioned, but only at moderate levels. The data does not

314 support this idea: while anti-coordinated punishers agreed more with the statement 'I did not 315 want to reduce Red's earnings by too much' than independent punishers did, this difference 316 was not significant $\left(\mu_{\mathrm{ACP}}=3.8, \mu_{\text {other punishers }}=3.5\right.$; MWU-test: $z=0.80$, d.f. $=1, P=0.423, r$ $317=0.06)$.

318 We further hypothesized that coordinated punishers might be only willing to punish if others do so too, because they do not want their payoffs to fall behind those of the other punisher.

320 Consistent with this hypothesis, we found that, among those participants who punished at 321 least once, coordinated punishers (CP) tended to agree the most with the statement 'I did not 322 want to earn less than Blue [the other punisher]' ( $\mu_{\mathrm{CP}}=4.9, \mu_{\text {other punishers }}=4.6$; MWU-test: $z=$ 3232.09 , d.f. $=1, P=0.036, r=0.12$ ). Another rationale for coordinated punishment might be 324 that they see punishment by the other group member as a nice act (enforcing a norm of 
cooperation) and feel the need to reciprocate. This idea is supported by the observation that coordinated punishers agreed most with the statement 'I did not want to let Blue [the other punisher] down in case they chose to punish' $\left(\mu_{\mathrm{CP}}=4.9, \mu_{\text {other punishers }}=4.5\right.$; MWU-test: $z=$ 2.26, d.f. $=1, P=0.024, r=0.13$ ). Finally, coordinated punishers may be unsure what to do when making their punishment decisions, or be unsure whether punishment is socially appropriate or legitimate ${ }^{15,53}$, and take others' punishment behaviour as a 'principle of social proof $^{72}$. We did not find support for these possible motives: coordinated punishers did not agree more with the statements 'When making my [conditional punishment] decisions, I was unsure what to do' $\left(\mu_{\mathrm{CP}}=4.0, \mu_{\text {other punishers }}=4.0\right.$; MWU-test: $z=0.11$, d.f. $=1, P=0.914, r=$ 0.01 ) or 'When making my [conditional punishment] decisions, I was unsure what was the appropriate thing to do' $\left(\mu_{\mathrm{CP}}=4.2, \mu_{\text {other punishers }}=4.1\right.$; MWU-test: $z=0.01$, d.f. $=1, P=$ $0.998, r=0.01)$.

Across our two sets of experiments, we find unambiguous evidence that many people like to condition their punishment decisions on those of other people. This conditionality is reminiscient of 'conditional cooperation', that is, many people's conditional willingness to contribute to a public good in the first place provided others do the same. This raises the interesting question whether conditional punishers are also conditional co-operators. We therefore now examine how preferences for conditional punishment (i.e. negative reciprocity) relate to well-studied preferences for conditional cooperation (i.e. positive reciprocity) ${ }^{73}$. That is, are these preferences linked and do they reflect a general sensitivity to social influence by peers, or are they unrelated, indicating that inclinations to reciprocate are context-specific? Existing evidence, which, with exceptions ${ }^{62,74}$, only looked at cooperation and punishment decisions and did not elicit conditional preferences, suggests that positive and negative reciprocity are unrelated ${ }^{75}$. However, given that conceptually, cooperation and punishment share the logic of a public good (while both cooperation and punishment are individualy costly, all group members may benefit), one might expect that people who prefer to cooperate conditionally on others' cooperation also prefer to condition their punishment on others' punishment. To test this hypothesis, we conducted a follow-up experiment examining whether individuals' punishment preferences are related to their preferences for conditional cooperation.

Two weeks after participating in our conditional punishment experiments (both from the original and the new study reported above), a subset of participants who were in the role of a 
punisher was re-invited to participate in an additional study (see below for subset details). In this follow-up experiment, participants were randomly matched with a partner to play a oneshot dyadic binary Prisoner's Dilemma Game, in which both players had to choose to either 'cooperate' or 'defect'. From the perspective of an individual participant, defecting yielded a personal benefit of 3 monetary units (MU), and $0 \mathrm{MU}$ for their partner. Cooperating yielded 2 MU for both partners (for instructions, see Supplementary Methods).

363

364

As in the primary experiment, participants in the follow-up experiment had to make two types of decisions: an 'unconditional' and a 'conditional' decision ${ }^{76}$. After their unconditional decision to either 'cooperate' or 'defect', participants entered a second ('conditional') stage in which they could make their cooperation decision dependent on the cooperation decision of their partner. Again, we recorded these conditional cooperation decisions using the strategy $\operatorname{method}^{76}$ : participants indicated their decision in case their partner would either cooperate or defect. Within a pair, earnings were determined by implementing the unconditional decision of one randomly chosen partner and the corresponding conditional decision of the other partner (Methods). This procedure allows us to classify participants into three distinct cooperation types ${ }^{14,74}$ : 'conditional cooperators' (those who cooperate only if their partner cooperates, but defect otherwise), 'free riders' (those who always defect irrespective of their partner), and 'others' (those who fall under neither of the first two categories).

To ensure sufficient statistical power, we selectively re-invited participants to obtain a more balanced sample with respect to the distribution of punishment types, compared to our full sample from the primary experiment. That is, we aimed to oversample those who punished at least once in the conditional stage in the primary experiment ( $c f$. Figure 2), and undersample those who never punished. This procedure indeed led to a more evenly distributed sample with respect to punishment types: among the $N=381$ participants in the follow-up experiment, $39 \%$ were non-punishers, $22 \%$ were unconditional punishers, $23 \%$ were coordinated punishers, and $16 \%$ were anti-coordinated punishers. In this sample we find a commonly observed pattern with regard to the distribution of cooperation types: more than half of the people (56\%) are conditional cooperators, about $28 \%$ are free riders, and the remaining $16 \%$ are classified as 'others'.

To investigate whether preferences for conditional cooperation and conditional punishment are linked at the individual level, we compare the distribution of punishment types across the different cooperation types. If these two types of preference reflect a more general 
behavioural tendency (e.g., inclinations to reciprocate, or to conform with the behaviour of others), we would expect that coordinated punishment is particularly frequent among conditional cooperators.

We find no evidence for a systematic relation between preferences for conditional cooperation and preferences for conditional punishment (Figure 4). The overall distribution of conditional punishment types does not differ across the cooperation types $\left(\chi^{2}(6)=5.26, P=0.510, \varphi_{c}=\right.$ 0.08). Furthermore, individuals with preferences for coordinated punishment were not disproportionately more likely to have preferences for conditional cooperation $\left(\chi^{2}(1)=0.71, P\right.$ $\left.=0.401, \varphi_{c}=0.04\right)$. Interestingly, free riders who, by definition, are unwilling to contribute to a first-order public good, are not less likely to contribute to the second-order public good of punishment compared with conditional cooperators. That is, their preference for conditional punishment is not different from those of conditional cooperators $\left(\chi^{2}(3)=2.25, P=0.522, \varphi_{c}\right.$ $=0.08)$. These results suggest that conditional preferences in positive and negative reciprocity do not follow the same logic ${ }^{74}$. Positive effects of peer behaviour do not, for example, reflect a simple conformist heuristic of blindly following others.

Our large-scale experiments provide firm empirical evidence that many people prefer to coordinate their punishment in cooperative interactions. Our results support theories that explain the emergence and maintenance of human cooperation based on individuals sanctioning their peers jointly rather than individually ${ }^{5}$. When deciding whether or not to punish a peer, many people are more willing to engage in costly punishment if others do so too. Intriguingly, preferences for coordinated punishment are particularly pronounced among those who do not punish unconditionally, suggesting that punishment levels can rise substantially when people have the opportunity to coordinate their sanctions.

Our results indicate that conditional preferences are not limited to the domain of positive reciprocity (cooperation), but extend to the domain of negative reciprocity (punishment), too. On aggregate, in both domains conditional preferences lead individuals to align their decisions with others and conform to their actions. However, there is substantial heterogeneity in how individuals condition their punishment on the punishment behaviour of others (Figure 2). Interestingly, our data suggest that people's conditional preferences in the domains of positive and negative reciprocity are unrelated (Figure 4). This result supports the emerging view that behavioural strategies of cooperation and punishment are not closely associated with each other ${ }^{14,74,75,77-80}$, and suggests that cooperation and punishment are separate 
phenomena, each driven by its own psychological processes. Indeed, the lack of correlation

422 between conditional punishment and conditional cooperation indicates that, while first-order and second-order free rider problems may look theoretically very similar, the underlying mechanisms supporting behaviour in them may be quite distinct.

Our analysis of anger levels provides a first step in understanding the possible drivers of conditional punishment. 'Independent punishers' - who punished regardless of the punishment of others - reported the highest levels of anger. This indicates that negative emotions are an important factor explaining punishment behaviour in our experiment. Interestingly, we observe lower levels of anger for individuals who condition their punishment on that of others ('coordinated punishers' who only punished if the other punished as well, and 'anti-coordinated punishers' who punished only if the other refrained from punishment). This suggests that, compared to independent punishers, the preferences of conditional punishers might perhaps reflect a more deliberative attitude, with behaviour relatively less likely to be driven by negative emotions.

435 Our additional questionnaires provide further correlational hints regarding possible motivations underlying conditional punishment preferences. Independent punishment was associated with a desire to mete out punishment oneself, supporting the idea that this preference might be driven by a 'thirst for revenge'. By contrast, preferences for coordinated punishment were linked with increased concerns for equality and not letting the other punisher down, suggesting (positive) reciprocity towards the other punisher. While these questionnaire results provide some initial indication of why people might prefer to punish conditionally, the observed differences between the punishment types were relatively small.

443 Moreover, our examination of the possible motivations is by no means exhaustive, and we 444 consider our current analysis to be a first step. Systematically uncovering the motivations 445 underlying conditional punishment preferences would be an interesting direction for future 446 study, which could contribute to a more comprehensive understanding of the psychological 447 determinants of peer punishment.

448 We conducted our experiments online, with American participants from Amazon Mechanical 449 Turk. This platform is well suited for large-scale studies like ours, and gives the opportunity 450 to recruit a more demographically diverse sample than student samples typically recruited in 451 laboratory studies ${ }^{81}$. Although collecting data online is associated with reduced levels of 452 experimental control relative to the traditional decision making laboratory, this does not have 
453 to compromise data quality ${ }^{82-84}$, especially when the methodological challenges of conducting 454 experiments online are adequately addressed ${ }^{29}$. Moreover, a recent study on cooperation and 455 punishment found that MTurkers punish in a similar way as students in the $1 \mathrm{~b}^{29}$, giving 456 reason to be optimistic about the generalizability of our results. However, it is an empirical 457 question whether the patterns of conditional punishment preferences from our study would be 458 observed under more standard laboratory conditions, or, for example, in samples from 459 different cultural backgrounds.

460 We designed our experiments to identify preferences for conditional punishment in a highly 461 controlled experimental scenario that isolates the impact of a peer's punishment behaviour on 462 people's tendencies to punish. At the same time, our design strived to minimize potential 463 confounding effects due to factors like non-anonymity, the possibility of future interactions 464 with those you punish, or anticipated counter-punishment. Of course, using a stylized social 465 context comes at a cost of realism, and might limit the generalisability of experimental 466 findings. In our case, the observed strong association between conditional punishment types 467 and (self-reported) anger suggests that decisions in our experiment are at least partly 468 motivated by factors that are commonly considered to drive punishment in the wild. 469 Nevertheless, studies of conditional punishment in more contextualized settings ${ }^{85,86}$ would 470 make valuable complements to the experiments presented here.

471 Our study set out to investigate preferences for conditional punishment in a very simple and 472 'minimal' environment: that is, one which is just complex enough to allow clean tests for 473 conditional punishment preferences. While we judge this is the right place to conduct initial 474 tests for such preferences, having provided clear evidence for them, we believe that 475 incrementally increasing the complexity of the experimental decision-making situation (i.e., 476 the number of factors at play) will help achieve a more complete empirical understanding of 477 conditional punishment. Interesting extensions of our basic experiment would include non478 linear returns to scale of punishment ${ }^{87}$. For example, coordinated sanctions might be more 479 efficient than individual, uncoordinated punishment, and less risky for those who mete them 480 out as revenge is less likely ${ }^{5}$. Testing whether anticipating such 'synergy' modulates people's 481 preferences for coordinated punishment would be of great value. Further experiments could 482 test how coordinated punishment impacts the long-run dynamics of cooperation. When time 483 horizons are longer than the one-shot interactions used in our study, decisions to cooperate 484 and punish have a strategic dimension, potentially involving interactions between coordinated 
punishment and individuals' reputation. Such experiments could also test the theoretically predicted deleterious implications of anti-social punishment ${ }^{88,89}$ in situations where defectors coordinate their punishment and 'gang up' against cooperators ${ }^{90,91}$.

\section{Methods}

For the primary experiment, we recruited $N=2,004$ participants from Amazon Mechanical Turk, two thirds of whom $(N=1,336)$ had the role of Punisher (Figure 1). Participants completed the experiment in about 10 minutes and earned a flat fee of $\$ 0.50$ plus their earnings from the game. At the end of a session, monetary units were converted into money at the rate $10 \mathrm{MU}=\$ 1.00$. Total average earnings were $\$ 1.50$, which corresponds to an average hourly wage of $\$ 9.00$. Before the start of the PGG, each participant had to correctly answer a set of control questions designed to test their understanding of the interaction setting. Participants were all US citizens; 55\% were male, and their mean age was 32.7 years. The online experiment was developed with the software LIONESS ${ }^{92}$; code available upon request from the corresponding authors. Ethical approval was provided by the Research Ethics Committee at the School of Economics, University of Nottingham. All experimental instructions are documented in the Supplementary Methods.

Experimental sessions ended with a short questionnaire. In the questionnaire, we asked Punishers to indicate how angry they felt when they learned about the Target's PGG decision on a Likert scale from 1 (not angry at all) to 7 (very angry; see Supplementary Methods for exact question wording). We also recorded age and gender.

For the follow-up experiment, intended to measure preferences for conditional cooperation ${ }^{76}$, we recruited $N=177$ individuals who had participated in the primary experiment. The followup experiment was programmed in Qualtrics and took about 7-8 minutes. Participants were matched post-hoc to calculate their earnings, consisting of a flat fee of $\$ 0.50$ plus their earnings from the game, which were converted into money at the rate $5 \mathrm{MU}=\$ 1.00$. To calculate their game earnings, we matched 176 of the 177 participants in pairs. A random mechanism chose which type of decision was implemented for each partner. In particular, for one player the 'unconditional' cooperation decision was implemented (the first mover), while for the other player (the second mover) the corresponding conditional cooperation decision (depending on the first mover's decision) was implemented. The earnings for the remaining $\left(177^{\text {th }}\right)$ participant were calculated by using their unconditional cooperation decision and 
516 implement the corresponding conditional cooperation decision of a randomly chosen other 517 participant. Total average earnings were $\$ 1.25$, which corresponds to an average hourly wage 518 of $\$ 10.00$.

519 Our replication study had the same general setup as our original study. For the conditional 520 punishment experiments, we recruited $N=2,316$ additional participants on MTurk (all US 521 citizens; 53\% male, mean age 34.9 years; sample size based on a power analysis, presented in 522 Supplementary Figure 4). Relative to the original study, we made three changes: on top of the 523 control questions prior to the cooperation stage of the game (as used in the original study), we 524 added control questions prior to the punishment stage. Furthermore, we counterbalanced the 525 order of the 'unconditional' (Figure 1c) and the 'conditional stage' (Figure 1d,e), so that half 526 of the participants made their conditional punishment decisions first. Finally, we added a set 527 of questionnaire items directly probing possible motivations for conditional punishment 528 preferences, as well as items to explore links between conditional punishment preferences 529 with personality characteristics. These items and the analysis of participants' responses are 530 detailed in the Supplementary Results. We recruited $N=204$ individuals who participated in 531 the replication study for the follow-up experiment measuring preferences for conditional 532 cooperation, which was identical to the follow-up experiment from the original study.

533 Reported tests were two-tailed, unless stated otherwise. Sample sizes for the original study 534 were not based on an explicit power analysis due to a lack of directly comparable experiments 535 to base a power analysis on. We used the data from the original study to perform a power 536 analysis for the replication study (Supplementary Figure 4). After being matched into groups, 537 participants were randomly assigned a role (Punisher or Target). All Punishers encountered 538 both relevant conditions in the strategy method (one where the other participant chose to 539 punish, and one there they chose to not-punish). In the replication study, the order of the 540 unconditional and conditional decisions was counterbalanced between interaction groups. 541 Data collection and analysis were not performed blind to the conditions of the experiments. 542 No data from interaction groups who completed the experiment was excluded from the 543 reported analyses.

545 Data availability. All data underlying the results reported in our manuscript can be found on 546 Github at https://github.com/LucasMolleman/NHB CoordinatedPunishment. 
Code Availability. Analysis code (for STATA) can be found on Github at https://github.com/LucasMolleman/NHB_CoordinatedPunishment.

\section{References}

1. Fehr, E., Fischbacher, U. \& Gächter, S. Strong reciprocity, human cooperation, and the enforcement of social norms. Hum. Nat. 13, 1-25 (2002).

2. Bowles, S. \& Gintis, H. A Cooperative Species: Human Reciprocity and Its Evolution. (Princeton University Press, 2011).

3. Rand, D. G. \& Nowak, M. A. Human cooperation. Trends Cogn. Sci. (2013).

4. Henrich, J. The Secret of Our Success: How Culture Is Driving Human Evolution, Domesticating Our Species, and Making us Smarter. (Princeton University Press, 2015).

5. Boyd, R., Gintis, H. \& Bowles, S. Coordinated punishment of defectors sustains cooperation and can proliferate when rare. Science 328, 617-620 (2010).

6. Hamilton, W. D. The genetical evolution of social behaviour I and II. J. Theor. Biol. 7, 152 (1964).

7. Gintis, H. Game theory evolving: A problem-centered introduction to modeling strategic interaction. (Princeton University Press, 2000).

8. Dietz, T., Ostrom, E. \& Stern, P. C. The struggle to govern the commons. Science 302, 1907-1912 (2003).

9. Nowak, M. A. Five rules for the evolution of cooperation. Science 314, 1560-1563 (2006). 
10. Lehmann, L. \& Keller, L. The evolution of cooperation and altruism-a general framework and a classification of models. J. Evol. Biol. 19, 1365-1376 (2006).

11. Egas, M. \& Riedl, A. The economics of altruistic punishment and the maintenance of cooperation. Proc. R. Soc. Lond. B Biol. Sci. 275, 871-878 (2008).

12. Fischbacher, U. \& Gachter, S. Social preferences, beliefs, and the dynamics of free riding in public good experiments. Am. Econ. Rev. 100:1, 541-556 (2010).

13. Burton-Chellew, M. N., El Mouden, C. \& West, S. A. Social learning and the demise of costly cooperation in humans. Proc R Soc B 284, 20170067 (2017).

14. Gächter, S., Kölle, F. \& Quercia, S. Reciprocity and the tragedies of maintaining and providing the commons. Nat. Hum. Behav. 1, 650 (2017).

15. Boehm, C. Hierarchy in the Forest: Egalitarianism and the Evolution of Human Altruism. (Harvard University Press, 1999).

16. Sigmund, K. Punish or perish? Retaliation and collaboration among humans. Trends Ecol. Evol. 22, 593-600 (2007).

17. Guala, F. Reciprocity: Weak or strong? What punishment experiments do (and do not) demonstrate. Behav. Brain Sci. 35, 1-15 (2012).

18. Fehr, E. \& Schurtenberger, I. Normative foundations of human cooperation. Nat. Hum. Behav. 2, 458 (2018).

19. Ostrom, E., Walker, J. \& Gardner, R. Covenants with and without a sword: Selfgovernance is possible. Am. Polit. Sci. Rev. 404-417 (1992). 
589

590

591

592

593

594

595

596

597

598

599

600

601

602

603

604

605

606

607

608

609

20. Fehr, E. \& Gächter, S. Cooperation and punishment in public goods experiments. Am. Econ. Rev. 90, 980-994 (2000).

21. Fehr, E. \& Gächter, S. Altruistic punishment in humans. Nature 415, 137-140 (2002).

22. Henrich, J. et al. In search of homo economicus: behavioral experiments in 15 small-scale societies. Am. Econ. Rev. 91, 73-78 (2001).

23. Henrich, J. et al. Costly punishment across human societies. Science 312, 1767-1770 (2006).

24. Dreber, A., Rand, D. G., Fudenberg, D. \& Nowak, M. A. Winners don't punish. Nature 452, 348 (2008).

25. Herrmann, B., Thöni, C. \& Gächter, S. Antisocial punishment across societies. Science 319, 1362-1367 (2008).

26. Gächter, S., Renner, E. \& Sefton, M. The long-run benefits of punishment. Science 322, $1510-1510$ (2008).

27. Cubitt, R. P., Drouvelis, M. \& Gächter, S. Framing and free riding: emotional responses and punishment in social dilemma games. Exp. Econ. 14, 254-272 (2011).

28. Raihani, N. J., Thornton, A. \& Bshary, R. Punishment and cooperation in nature. Trends Ecol. Evol. 27, 288-295 (2012).

29. Arechar, A. A., Gächter, S. \& Molleman, L. Conducting interactive experiments online. Exp. Econ. 21, 99-131 (2018).

30. Panchanathan, K. \& Boyd, R. A tale of two defectors: the importance of standing for evolution of indirect reciprocity. J. Theor. Biol. 224, 115-126 (2003). 
610 31. Gardner, A. \& West, S. A. Cooperation and punishment, especially in humans. Am. Nat. $611 \quad \mathbf{1 6 4}, 753-764(2004)$.

612 32. Lehmann, L., Rousset, F., Roze, D. \& Keller, L. Strong reciprocity or strong ferocity? A 613 population genetic view of the evolution of altruistic punishment. Am. Nat. 170, 21-36 614 (2007).

615 33. Heckathorn, D. D. Collective action and the second-order free-rider problem. Ration. Soc. $616 \quad \mathbf{1}, 78-100(1989)$.

617 34. Panchanathan, K. \& Boyd, R. Indirect reciprocity can stabilize cooperation without the 618 second-order free rider problem. Nature 432, 499 (2004).

619 35. Sigmund, K., De Silva, H., Traulsen, A. \& Hauert, C. Social learning promotes 620 institutions for governing the commons. Nature 466, 861-863 (2010).

621 36. Barclay, P. Reputational benefits for altruistic punishment. Evol. Hum. Behav. 27, 325$622 \quad 344(2006)$.

623 37. dos Santos, M., Rankin, D. J. \& Wedekind, C. The evolution of punishment through 624 reputation. Proc. R. Soc. Lond. B Biol. Sci. 278, 371-377 (2011).

625 38. dos Santos, M., Rankin, D. J. \& Wedekind, C. Human cooperation based on punishment 626 reputation. Evolution 67, 2446-2450 (2013).

627 39. Raihani, N. J. \& Bshary, R. The reputation of punishers. Trends Ecol. Evol. 30, 98-103 $628 \quad(2015)$

629 40. Henrich, J. \& Boyd, R. Why people punish defectors. J. Theor. Biol. 208, 79-89 (2001). 
630

631

632

633

634

635

636

637

638

639

640

641

642

643

644

645

646

647

41. Boyd, R. \& Richerson, P. J. Punishment allows the evolution of cooperation (or anything else) in sizable groups. Ethol. Sociobiol. 13, 171-195 (1992).

42. Kiyonari, T. \& Barclay, P. Cooperation in social dilemmas: free riding may be thwarted by second-order reward rather than by punishment. J. Pers. Soc. Psychol. 95, 826 (2008).

43. Fu, T., Ji, Y., Kamei, K. \& Putterman, L. Punishment can support cooperation even when punishable. Econ. Lett. 154, 84-87 (2017).

44. Szolnoki, A., Szabó, G. \& Perc, M. Phase diagrams for the spatial public goods game with pool punishment. Phys. Rev. E 83, 036101 (2011).

45. Traulsen, A., Röhl, T. \& Milinski, M. An economic experiment reveals that humans prefer pool punishment to maintain the commons. Proc R Soc B rspb20120937 (2012).

46. Yamagishi, T. The provision of a sanctioning system as a public good. J. Pers. Soc. Psychol. 51, 110 (1986).

47. Ostrom, E. Governing the Commons. (Cambridge University Press, 2015).

48. Hilbe, C., Traulsen, A., Röhl, T. \& Milinski, M. Democratic decisions establish stable authorities that overcome the paradox of second-order punishment. Proc. Natl. Acad. Sci. 111, 752-756 (2014).

49. Szolnoki, A. \& Perc, M. Effectiveness of conditional punishment for the evolution of public cooperation. J. Theor. Biol. 325, 34-41 (2013).

50. FeldmanHall, O., Otto, A. R. \& Phelps, E. A. Learning moral values: Another's desire to punish enhances one's own punitive behavior. J. Exp. Psychol. Gen. 147, 1211 (2018). 
650

651

652

653

654

655

656

657

658

659

660

661

662

663

664

665

666

667

668

669

51. Son, J.-Y., Bhandari, A. \& FeldmanHall, O. Crowdsourcing punishment: Individuals reference group preferences to inform their own punitive decisions. (2019). doi:doi:10.31234/osf.io/ph3wn

52. Mahdi, N. Q. Pukhtunwali: Ostracism and honor among the Pathan hill tribes. Ethol. Sociobiol. 7, 295-304 (1986).

53. Wiessner, P. Norm enforcement among the Ju/'hoansi Bushmen. Hum. Nat. 16, 115-145 (2005).

54. Mathew, S. \& Boyd, R. Punishment sustains large-scale cooperation in prestate warfare. Proc. Natl. Acad. Sci. 108, 11375-11380 (2011).

55. Gürerk, Ö., Irlenbusch, B. \& Rockenbach, B. The competitive advantage of sanctioning institutions. Science 312, 108-111 (2006).

56. Ertan, A., Page, T. \& Putterman, L. Who to punish? Individual decisions and majority rule in mitigating the free rider problem. Eur. Econ. Rev. 53, 495-511 (2009).

57. Casari, M. \& Luini, L. Cooperation under alternative punishment institutions: An experiment. J. Econ. Behav. Organ. 71, 273-282 (2009).

58. Casari, M. \& Luini, L. Peer punishment in teams: expressive or instrumental choice? Exp. Econ. 15, 241-259 (2012).

59. Kamei, K. Conditional punishment. Econ. Lett. 124, 199-202 (2014).

60. Cheung, S. L. New insights into conditional cooperation and punishment from a strategy method experiment. Exp. Econ. 17, 129-153 (2014). 
61. Peysakhovich, A. \& Rand, D. G. Habits of virtue: Creating norms of cooperation and defection in the laboratory. Manag. Sci. 62, 631-647 (2015).

62. Albrecht, F., Kube, S. \& Traxler, C. Cooperation and Norm Enforcement-The IndividualLevel Perspective. Journal of Public Economics 1 (2017).

63. Selten, R. Die Strategiemethode zur Erforschung des eingeschränkt rationalen Verhaltens im Rahmen eines Oligopolexperimentes. in (Seminar für Mathemat. Wirtschaftsforschung u. Ökonometrie, 1965).

64. Bosman, R. \& Van Winden, F. Emotional hazard in a power-to-take experiment. Econ. J. 112, 147-169 (2002).

65. Falk, A., Fehr, E. \& Fischbacher, U. Driving forces behind informal sanctions. Econometrica 73, 2017-2030 (2005).

66. Hopfensitz, A. \& Reuben, E. The importance of emotions for the effectiveness of social punishment. Econ. J. 119, 1534-1559 (2009).

67. Nelissen, R. M. A. \& Zeelenberg, M. Moral emotions as determinants of third-party punishment: Anger, guilt, and the functions of altruistic sanctions. Judgm. Decis. Mak. 543 (2009).

68. Gächter, S. \& Herrmann, B. Reciprocity, culture and human cooperation: previous insights and a new cross-cultural experiment. Philos. Trans. R. Soc. B Biol. Sci. 364, 791806 (2009).

69. Gächter, S. \& Herrmann, B. The limits of self-governance when cooperators get punished: Experimental evidence from urban and rural Russia. Eur. Econ. Rev. 55, 193$210(2011)$ 
70. Elster, J. Norms of revenge. Ethics 100, 862-885 (1990).

693 71. Nikiforakis, N. Punishment and counter-punishment in public good games: Can we really 694 govern ourselves? J. Public Econ. 92, 91-112 (2008).

695 72. Cialdini, R. B. \& Trost, M. R. Social Influence: Social Norms, Conformity and 696 Compliance. in The handbook of social psychology, Vols. 1 and 2 (4th ed.) (eds. Gilbert, 697 D. T., Fiske, S. T. \& Lindzey, G.) 151-192 (McGraw-Hill, 1998).

698 73. Thöni, C. \& Volk, S. Conditional cooperation: Review and refinement. Econ. Lett. 171, $699 \quad 37-40(2018)$.

74. Weber, T. O., Weisel, O. \& Gächter, S. Dispositional free riders do not free ride on punishment. Nat. Commun. 9, 2390 (2018).

75. Peysakhovich, A., Nowak, M. A. \& Rand, D. G. Humans display a 'cooperative 703 phenotype'that is domain general and temporally stable. Nat. Commun. 5, 4939 (2014).

704 76. Fischbacher, U., Gächter, S. \& Fehr, E. Are people conditionally cooperative? Evidence 705 from a public goods experiment. Econ. Lett. 71, 397-404 (2001).

706 77. Dohmen, T., Falk, A., Huffman, D. \& Sunde, U. Homo reciprocans: Survey evidence on 707 behavioural outcomes. Econ. J. 119, 592-612 (2009).

708 78. Yamagishi, T. et al. Rejection of unfair offers in the ultimatum game is no evidence of 709 strong reciprocity. Proc. Natl. Acad. Sci. 109, 20364-20368 (2012).

710 79. Egloff, B., Richter, D. \& Schmukle, S. C. Need for conclusive evidence that positive and 711 negative reciprocity are unrelated. Proc. Natl. Acad. Sci. U. S. A. 110, E786-E786 (2013). 
80. Eriksson, K., Cownden, D., Ehn, M. \& Strimling, P. 'Altruistic' and 'Antisocial' Punishers are One and the Same. Rev. Behav. Econ. 1, 209-221 (2014).

81. Difallah, D. E., Catasta, M., Demartini, G., Ipeirotis, P. G. \& Cudré-Mauroux, P. The dynamics of micro-task crowdsourcing: The case of amazon mturk. in Proceedings of the 24th international conference on world wide web 238-247 (International World Wide Web Conferences Steering Committee, 2015).

82. Paolacci, G., Chandler, J. \& Ipeirotis, P. G. Running experiments on amazon mechanical turk. Judgm. Decis. Mak. 5, 411-419 (2010).

83. Horton, J. J., Rand, D. G. \& Zeckhauser, R. J. The online laboratory: Conducting experiments in a real labor market. Exp. Econ. 14, 399-425 (2011).

84. Berinsky, A. J., Huber, G. A. \& Lenz, G. S. Evaluating online labor markets for experimental research: Amazon. com's Mechanical Turk. Polit. Anal. 20, 351-368 (2012).

85. Balafoutas, L., Nikiforakis, N. \& Rockenbach, B. Direct and indirect punishment among strangers in the field. Proc. Natl. Acad. Sci. 111, 15924-15927 (2014).

86. Balafoutas, L., Nikiforakis, N. \& Rockenbach, B. Altruistic punishment does not increase with the severity of norm violations in the field. Nat. Commun. 7, 13327 (2016).

87. Raihani, N. J. \& Bshary, R. The evolution of punishment in n-player public goods games: A volunteer's dilemma. Evolution 65, 2725-2728 (2011).

88. Rand, D. G. \& Nowak, M. A. The evolution of antisocial punishment in optional public goods games. Nat. Commun. 2, 434 (2011). 
89. Garcia, J. \& Traulsen, A. Leaving the loners alone: Evolution of cooperation in the presence of antisocial punishment. J. Theor. Biol. 307, 168-173 (2012).

90. McCabe, C. M. \& Rand, D. G. Coordinated punishment does not proliferate when defectors can also punish cooperators. J. Commun. Res. 6, (2014).

91. Huang, F., Chen, X. \& Wang, L. Conditional punishment is a double-edged sword in promoting cooperation. Sci. Rep. 8, 528 (2018).

92. Giamattei, M., Molleman, L., Seyed Yahosseini, K. \& Gächter, S. LIONESS Lab - a free web-based platform for conducting interactive experiments online. Available at SSRN: https://ssrn.com/abstract=3329384 or http://dx.doi.org/10.2139/ssrn.3329384. (Social Science Research Network, 2019).

93. Wooldridge, J. M. Econometric Analysis of Cross Section and Panel Data. (MIT press, 2010).

Acknowledgements. We thank B. Beranek, P. van den Berg, J. Schulz, T. Weber and O. Weisel for insightful comments and useful discussions. This work was supported by the European Research Council [grant number ERC-AdG 295707 COOPERATION], the Economic and Social Research Council [grant numbers ES/K002201/1 and ES/P008976/1], the Nottingham School of Economics and the Center of Adaptive Rationality, Max Planck Institiute for Human Development Berlin. L.M. was further supported by the Open Research Area grant ASTA [grant number 176] and the Amsterdam Brain and Cognition Project Grant 2018. The funders had no role in study design, data collection and analysis, decision to publish, or preparation of the manuscript.

Author contributions. L.M., F.K., C.S. and S.G. designed the study, L.M. and F.K. collected and analysed the data, L.M., F.K., C.S. and S.G. wrote the paper.

Competing interests. The authors declare no competing interests. 
761 Materials \& Correspondence. Please contact L.M. for correspondence and material 762 requests. 


\section{Figure legends}

764 Figure 1 | Experimental sequence. a, Participants are assigned to a group of three (grey

765 circles) and make a binary decision in a public goods game (PGG; grey arrows). b, Roles are

766 randomly allocated among group members: two Punishers (P1 and P2; blue circles) and one

767 Target (T; orange circle); T's PGG decision is revealed to P1 and P2 but no information about

768 the other Punisher's PGG decision is provided; Punishers are informed about the steps

769 comprising the punishment procedure. c, P1 and P2 each make an unconditional binary

770 decision whether or not to punish T (blue hatched bolts). d,e, P1 and P2 make conditional

771 binary punishment decisions; shown is the situation from the perspective of P2. First, they

772 decide whether they would punish in case the other P player chose to not punish (d; empty

773 bolt) in step c; or to punish (e; solid bolt) in step c. Once all decisions have been made, P1 or

$774 \mathrm{P} 2$ is randomly selected and their unconditional punishment decision (step c) is implemented,

775 along with the corresponding conditional decision of the other P player (step d or e). For

776 experimental instructions, see Supplementary Methods. 


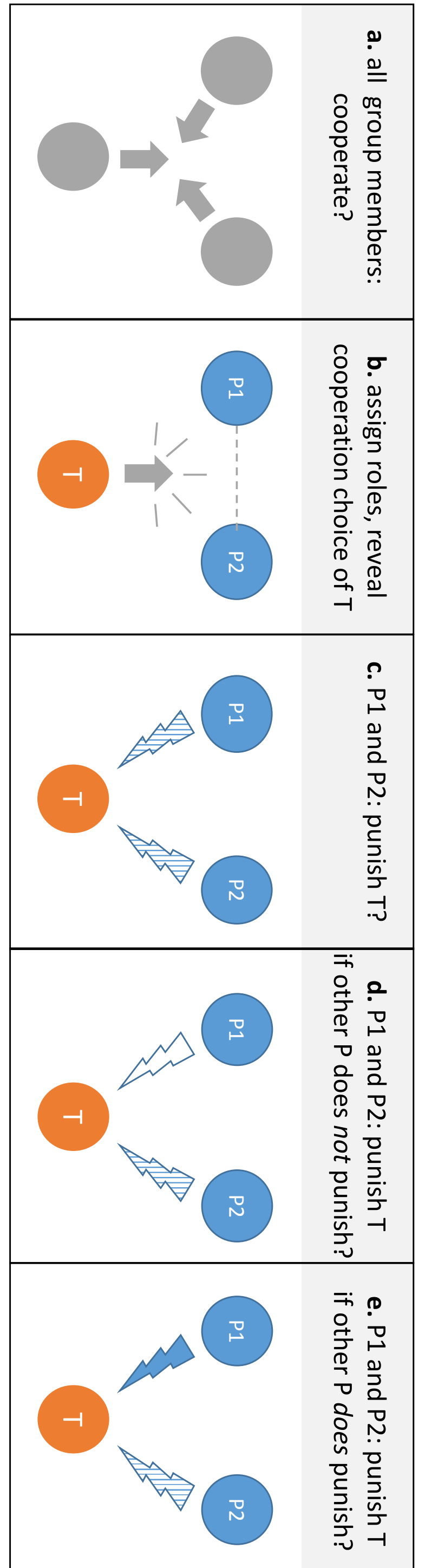


777 Figure 2 | Distribution of punishment types by decision in unconditional punishment

778 stage. Bars show data from the strategy method, restricted to those individuals who punished 779 at least once $(N=282$ out of the total of $N=1,336)$. a, All punishers. b, Only those who did 780 not punish in the unconditional punishment stage. c, Only those who did punish in the 781 unconditional punishment stage. 

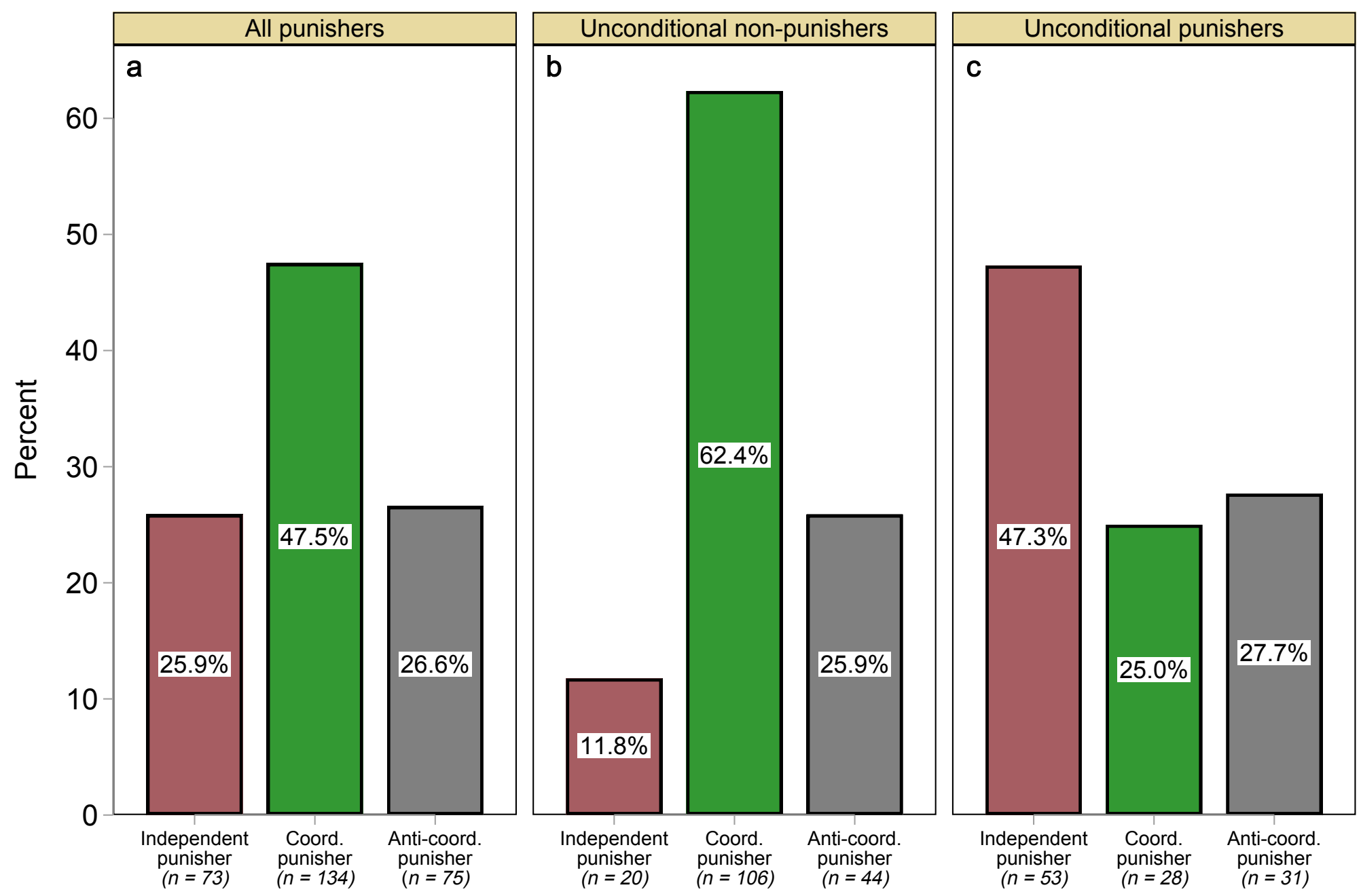
782 Figure 3 | Anger levels per punishment type. Panels show distributions of Punishers'self783 reported ratings of anger when they learned about the PGG decision of their Target. The 784 distribution of anger levels differ significantly across punishment types (Kruskal-Wallis test: $785 \chi^{2}=198.29$, d.f. $\left.=3, P<0.001\right)$. 


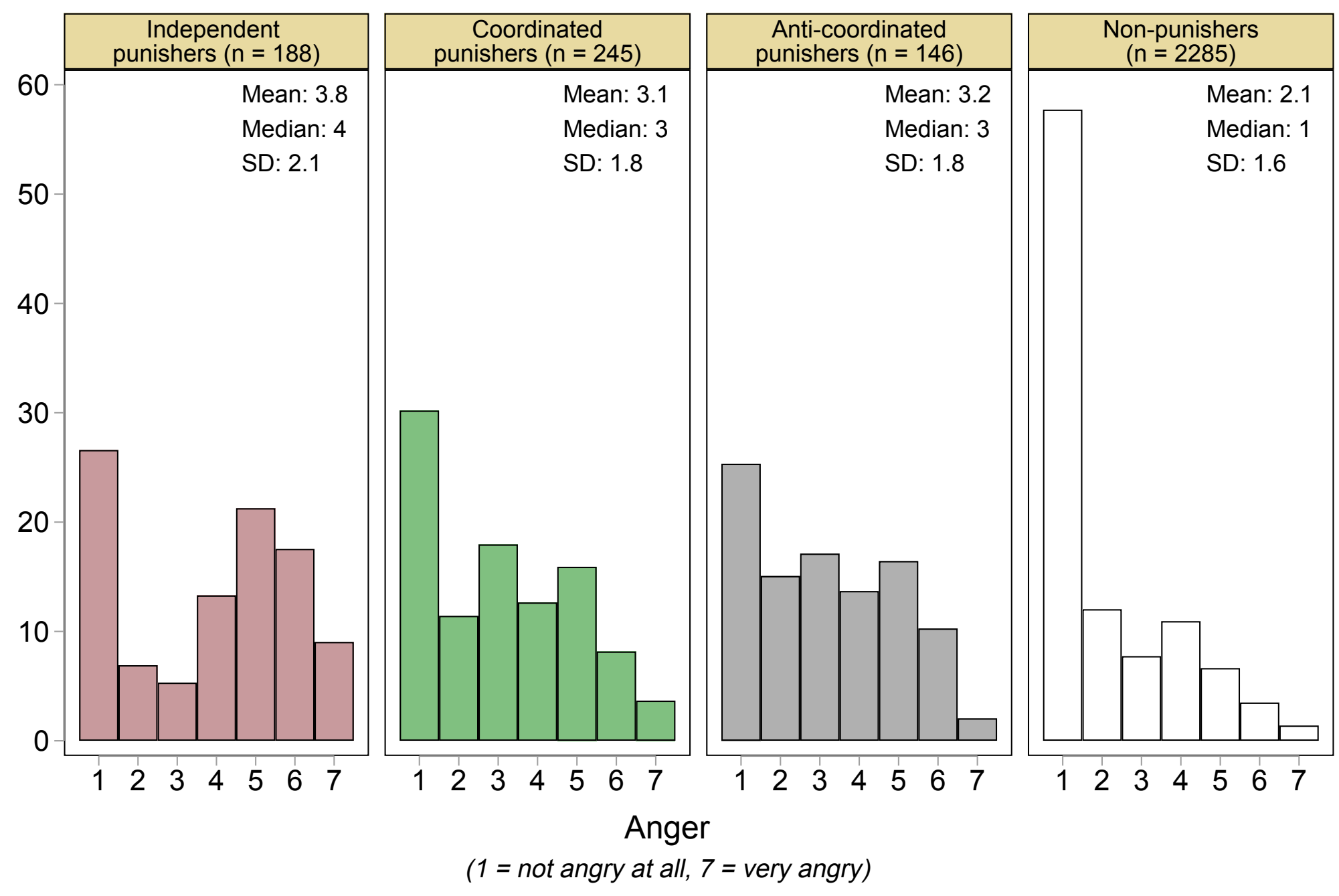


786 Figure 4 | The (lack of) correlation between individuals' preferences for conditional

787 cooperation and conditional punishment. Stacked bars show the distribution of punishment

788 types as measured in the primary experiment, separated by conditional cooperation type as

789 measured in the follow-up experiment. 


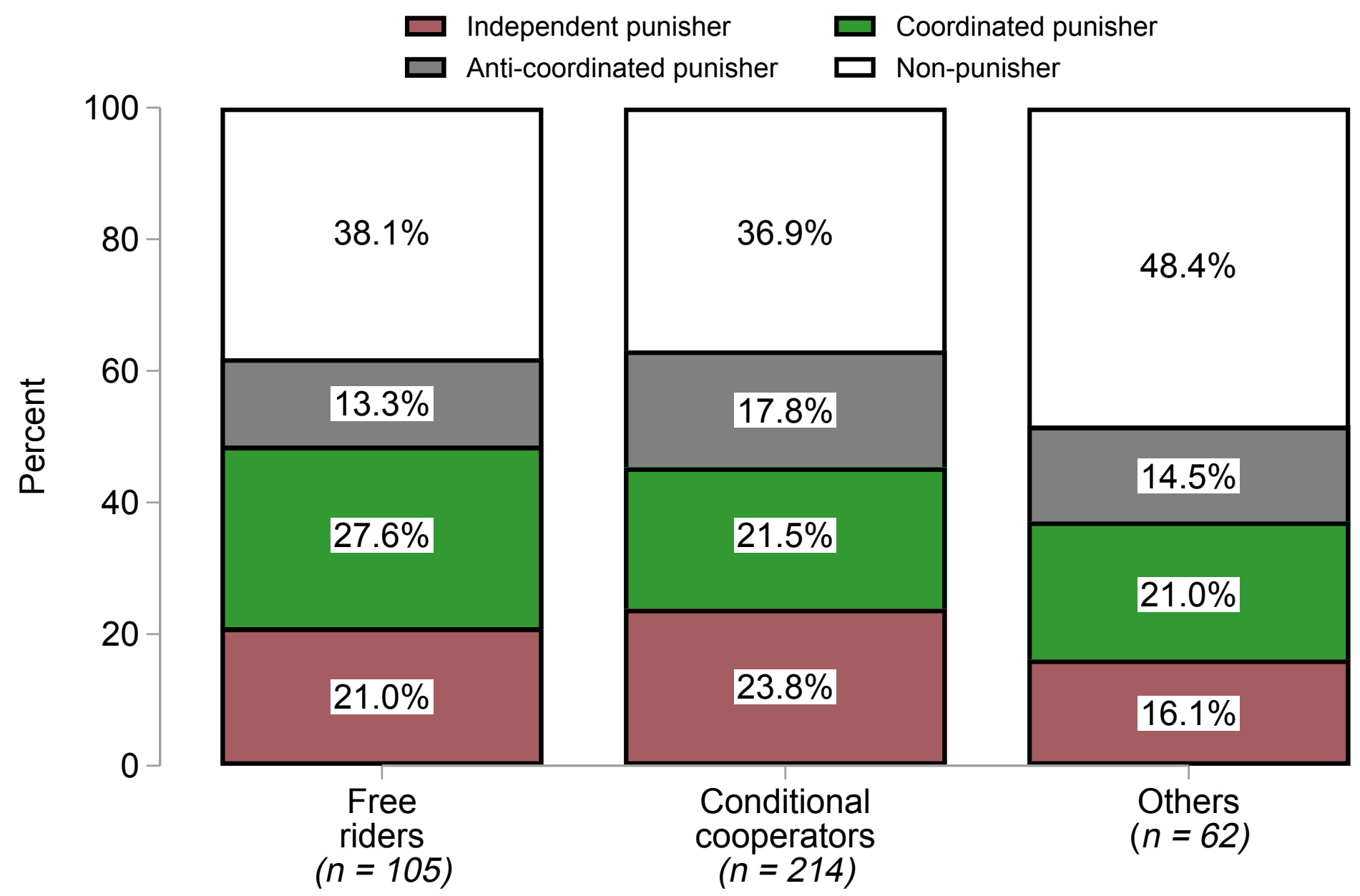




\section{Tables}

791 Table 1 | Behavioural determinants of conditional punishment. Coefficients from logistic

792 generalized linear mixed models fitted to Punishers' decisions whether or not to punish the

793 Target ( 1 if yes, 0 if no). 'Other punishes' is a dummy variable with value 1 in case the other

794 Punisher punishes and 0 otherwise. 'Unconditional punishment decision' is a dummy variable

795 indicating whether a participant punished unconditionally $(=1)$ or not $(=0)$. 'Unconditional

796 punishment $\times$ Other punishes' is an interaction term between the two variables. 'Target

797 cooperated' is a dummy variable with value 1 if the Target cooperated and 0 if she defected.

798 'Target cooperated' $\times$ Other punishes' is an interaction term between this variable and others'

799 punishment decision to test whether coordinated punishment varies with the Target's

800 cooperation decision. Additional regressions including controls for gender and age revealed

801 that neither of these demographic items has a significant effect. Including gender and age did

802 not significantly change any of the effects reported above. We cluster standard errors at the

803 individual level, correcting for repeated observations ${ }^{93} .95 \%$ confidence interval in brackets

804 and p-values in parentheses. 
Dependent variable:

Punish ( 1 if yes, 0 otherwise)

(1)

(2)

Other punishes

(1 if other Punisher punished, 0 otherwise)

$$
\begin{gathered}
0.734 \\
(<0.001) \\
{[0.447-1.022]} \\
\\
3.074 \\
(<0.001) \\
{[2.666-3.481]} \\
-0.814 \\
(0.001) \\
{[-1.306--0.322]}
\end{gathered}
$$$$
0.380
$$$$
(<0.001)
$$$$
[0.155-0.605]
$$

Unconditional punishment

Unconditional punishment $\times$ Other punishes

Target cooperated

(1 if Target cooperated, 0 otherwise)

$-0.831$

$(<0.001)$

$[-1.120--0.463]$

Target cooperated $\times$ Other punishes

$(0.854)$

[-0.373-0.450]

Constant

$\begin{array}{cc}-2.862 & -1.750 \\ (<0.001) & (<0.001) \\ 114--2.610] & {[-1.960--1.541]}\end{array}$

Number of observations

2,672

2,672

Number of participants

1,336

1,336

805 


\section{Supplementary Figures}

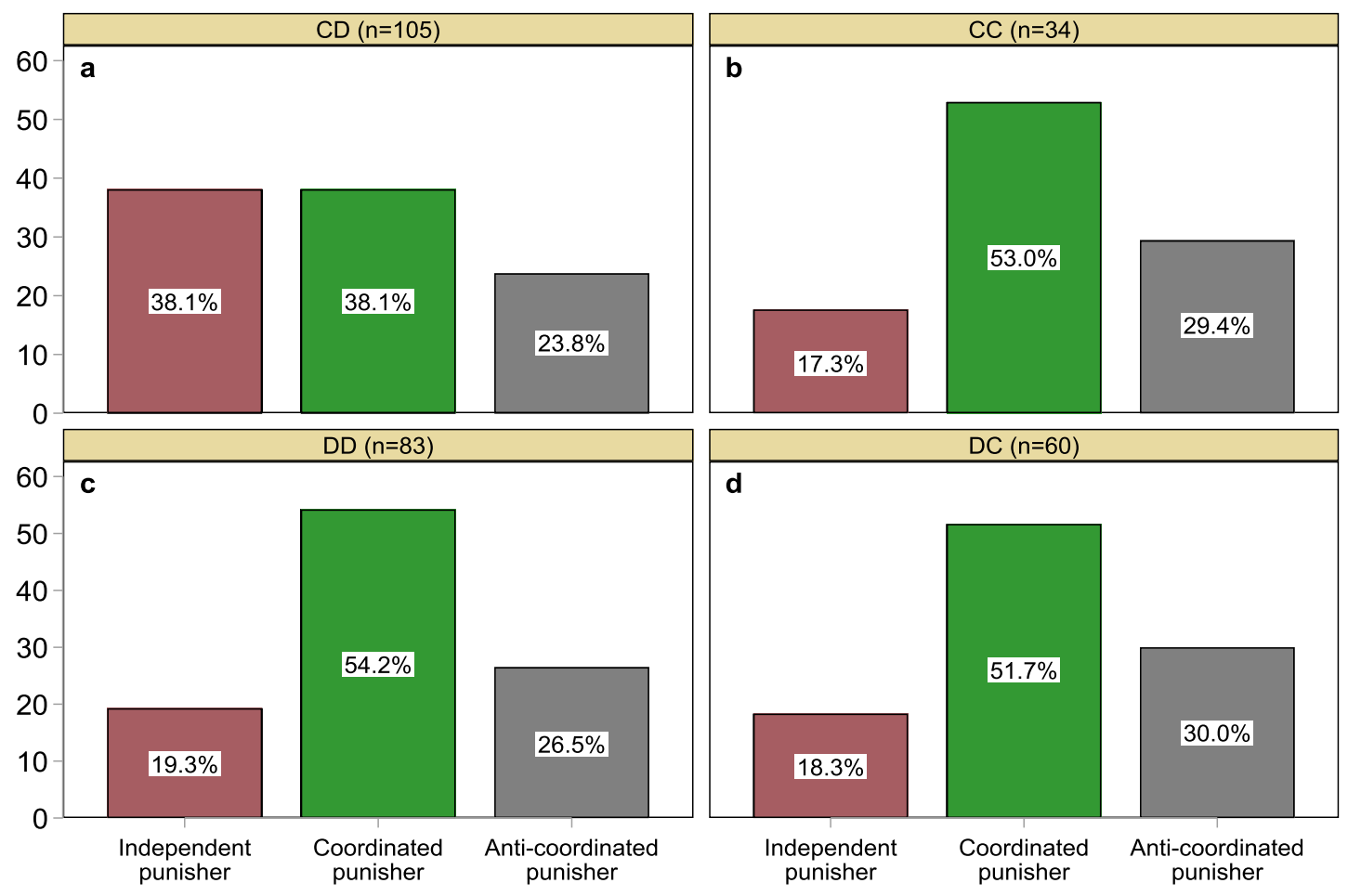

Supplementary Figure 1 | Conditional punishment types broken down by outcome of the Public Goods Game (PGG). Bars reflect data from the strategy method, and includes only those individuals who punished at least once in the conditional stage $(N=282$ out of the total of $N=$ 1,336). a, Punisher cooperated, Target defected (CD). b, Punisher and Target cooperated (CC). c, Punisher and Target defected (DD). d, Punisher defected, Target cooperated (DC). We observe that overall, coordinated punishers tend to be most frequent (52\% - 54\%). The exception to this general pattern is the case when the Punisher cooperated and the Target defected (panel a). For that outcome, the frequency of independent punishers is higher than in the other cases $\left(\chi^{2}(1)=12.99, P\right.$ $\left.<0.001, \varphi_{c}=0.21\right)$, and the frequency of coordinated punishers is lower $\left(\chi^{2}(1)=5.96, P=0.015, \varphi_{c}\right.$ $=0.15$; see Supplementary Table 2 below for a more detailed statistical analysis). For the other outcomes of the PGG, the fraction of independent punishers varies between 17\% and 19\%, and the fraction of anti-coordinated punishers varies between $27 \%$ and $30 \%$. Overall, the distribution of types is remarkably similar across these situations $\left(\chi^{2}(4)=0.25, P=0.993, \varphi_{c}=0.03\right)$. 


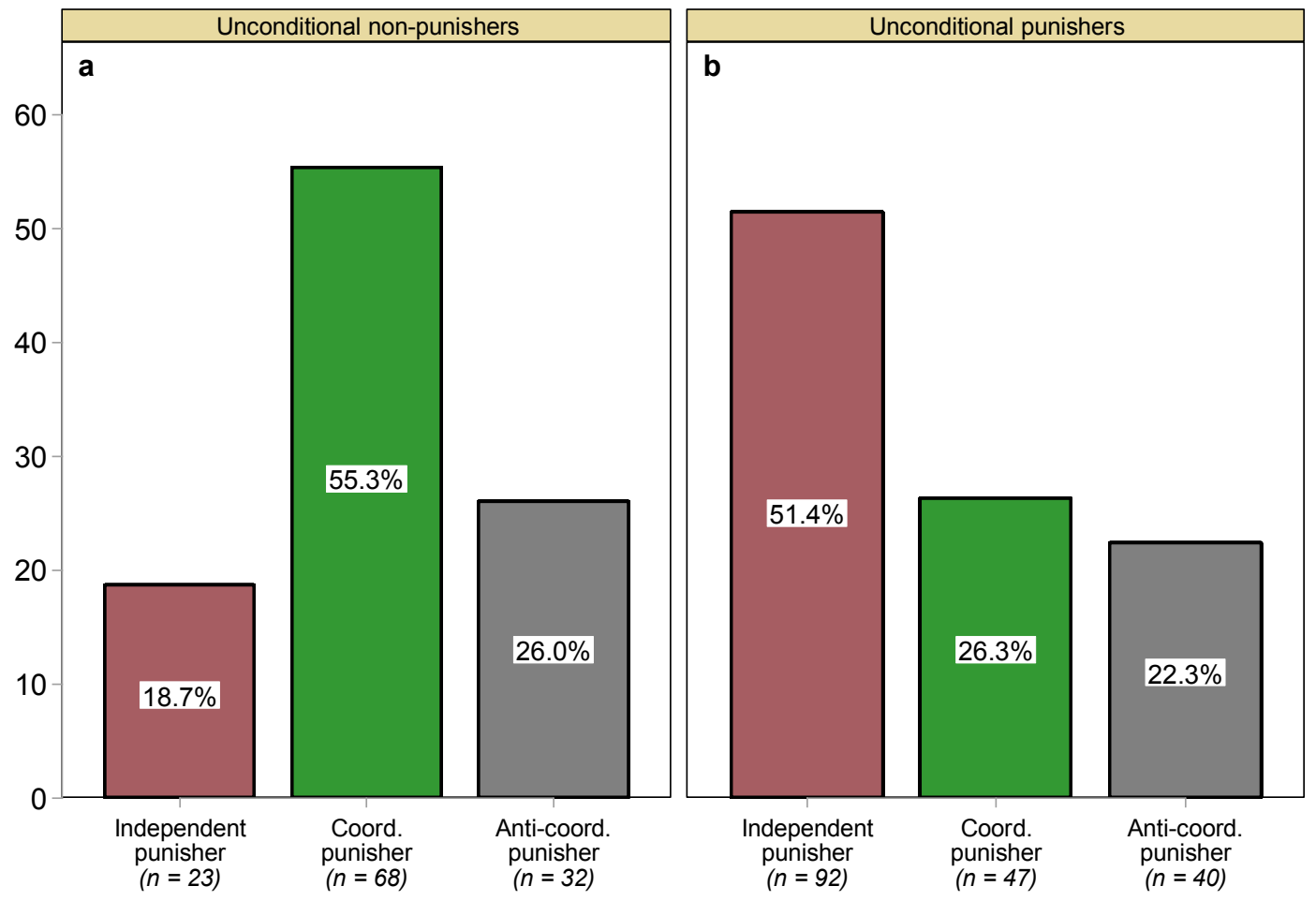

Supplementary Figure 2 | Distribution of punishment types in the replication study. Bars report data from the strategy method, restricted to those individuals who punished at least once $(N=$ 302 out of the total of $N=1,544)$. a, Only participants who did not punish unconditionally. $\mathbf{b}$, Only participants who did punish unconditionally. 


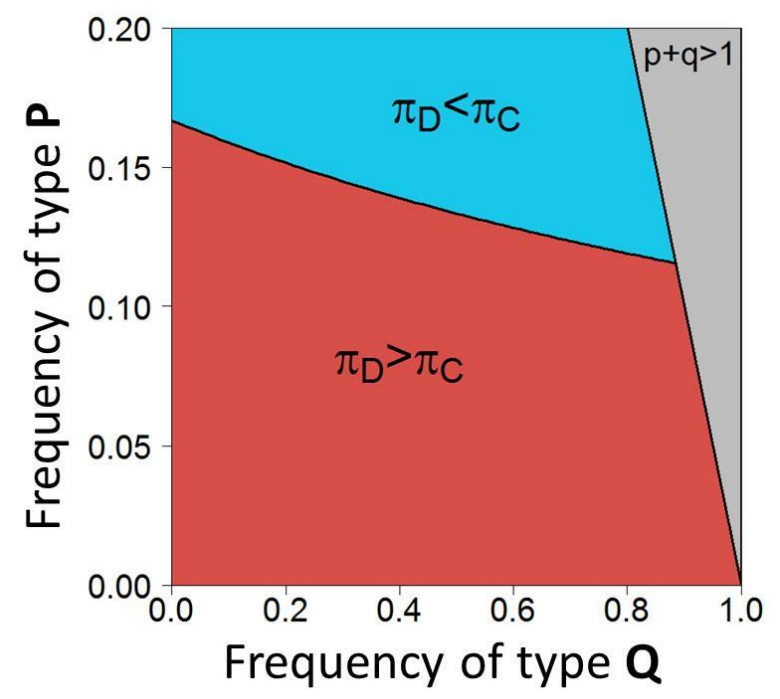

Supplementary Figure 3 | Relative payoffs of cooperation and defection depend on the relative frequencies of punishment types. This levelplot summarizes the analysis of the model presented in the Supplementary Results. The horizontal and vertical axes show the frequency of punishment types $Q$ and $P$, respectively. For each combination of frequencies of these punishment types, the colours indicate whether expected payoffs of cooperation are lower (red) or higher (blue) than expected payoffs of defection. Theoretically impossible cases (where the total frequency of $P$ and $Q$ would exceed 1) are shown in grey. The black line separating the red and blue areas indicates the values for which $\pi_{C}=\pi_{\mathrm{D}}$. That is, $p=\frac{c}{k(2+q)}$. For this illustration, we assume that $c=1$ and $k=3$. For full model details, see Supplementary Results, section "Effects of coordinated punishment on relative payoffs of cooperation and defection". 


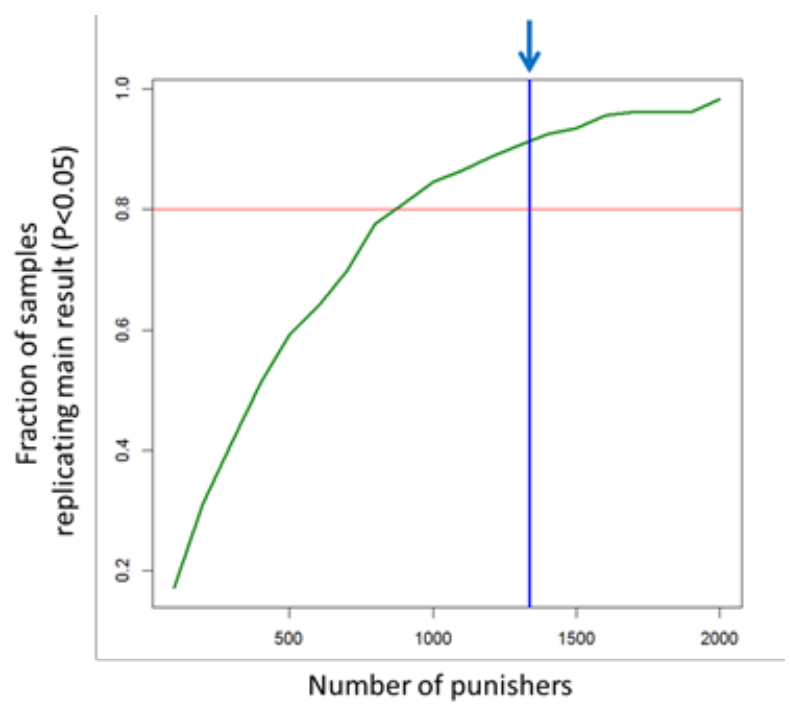

Supplementary Figure 4 | Power analysis for the additional study. Based on the data of our original experiments we calculated the probability to reproduce our main result ("people were more likely to punish their peers when the other punisher did so as well"; cf. Table 1, Model 1) for given sample sizes. For a range of possible sample sizes $N$, we sampled $N$ participants from our data (with replacement) who were in the role of Punisher, and ran Model (1) on that sample. For each $N$ we repeated that 1,000 times and tracked the number of replications in which the main effect was positive and significant at the $P<0.05$ level. The green line indicates the expected probability of detecting a significant result (at the 5\% significance level) as a function of the number of punishers in our sample. The vertical blue line indicates the sample size in our original submission; the horizontal red line indicates $80 \%$ probability of replicating our main result. The red and green line intersect at $\mathrm{N} \approx 800$, indicating that this number of Punishers is expected to have $80 \%$ power. Note that in our experimental setup, only $2 / 3$ of the participants are in the Punisher role, so we would require $(800 * 2 / 3=) 1,200$ participants. In our additional study, counterbalanced the order of the punishment decisions, aiming for 1,200 participants in both 'orders', yielding 2,400 participants in total. 


\section{Supplementary Tables}

Supplementary Table 1 | Determinants of conditional punishment in our replication study, and for all data pooled. Coefficients from logistic generalized linear mixed models fitted to Punishers' decisions whether or not to punish the Target ( 1 if yes, 0 if no). The models presented in this table mirror those from Table 1 of the main text. Models (1) and (2) use data from our replication study. Models (3) and (4) use all data, pooling across our main and our replication study. 'Other punishes' is a dummy variable with value 1 in case the other Punisher punishes and 0 otherwise. 'Unconditional punishment decision' is a dummy variable indicating whether a participant punished unconditionally $(=1)$ or not $(=0)$. 'Unconditional punishment $\times$ Other punishes' is an interaction term between the two variables. 'Target cooperated' is a dummy variable with value 1 if the Target cooperated and 0 if she defected. 'Target cooperated' $\times$ Other punishes' is an interaction term between this variable and others' punishment decision to test whether coordinated punishment varies with the Target's cooperation decision. Additional regressions including controls for gender and age revealed that neither of these demographic items has a significant effect. Including gender and age did not significantly change any of the effects reported above. We cluster standard errors at the individual level, correcting for repeated observations. 95\% confidence interval in brackets and p-values in parentheses.

Dependent variable:

Punish ( 1 if yes, 0 otherwise)

(1)

(2)

(3)

(4)

Other punishes

(1 if other Punisher punished, 0 otherwise)

0.533

$(<0.001)$

[0.241-0.825]

3.407

$(<0.001)$

[3.032-3.782]

Unconditional punishment $x$

Other punishes

$-0.408$

$(0.067)$

$[-0.844-0.028]$

Unconditional punishment
0.227

$(0.009)$

[0.055-0.397]

$(<0.001)$

[0.437-0.848]

3.246

$(<0.001)$

[2.973-3.519]

$-0.600$

$(<0.001)$

$[-0.925-0.276]$
$-1.342$

$(<0.001)$

$[-1.705--0.979]$
$-1.103$

$(<0.001)$

$[-1.360--0.846]$
0.087

(0.658)

$[-0.299-0.474]$
0.294

$(<0.001)$

[0.156-0.431]

(1)

Target cooperated

(1 if Target cooperated, 0 otherwise)
Target cooperated $\times$ Other punishes Target cooperated $\times$ Other punishes

Constant

$$
-3.129
$$$$
(<0.001)
$$$$
[-3.399--2.859]
$$

$$
\begin{gathered}
-1.500 \\
(<0.001)
\end{gathered}
$$

$[-1.679--1.320]$
$-2.994$

$(<0.001)$
0.075

$(0.598)$

$[-0.205-0.355]$

$-1.611$

$(<0.001)$

\begin{tabular}{lcccc} 
& {$[-3.399--2.859]$} & {$[-1.679--1.320]$} & {$[-3.179--2.810]$} & {$[-1.747--1.475]$} \\
\hline Number of observations & 3,088 & 3,088 & 5,760 & 5,760 \\
Number of participants & 1,544 & 1,544 & 2,880 & 2,880 \\
\hline
\end{tabular}


Supplementary Table 2 | Determinants of conditional punishment. Coefficients from logistic generalized linear mixed models fitted to Punishers' decisions whether or not to punish the Target (1 if yes, 0 if no). Model (1) uses data from our main experiment. Model (2) uses data from our replication study. Model (3) provides the results using all data. 'Other punishes' is a dummy variable that takes the value 1 in case the other Punisher punishes and 0 otherwise. Dummy variables CD (DC) indicate a situation in which a Punisher cooperated (defected) and the Target defected (cooperated), while CC indicates a situation where both players cooperated. The case where both the Punisher and the Target defected is the baseline. We include interaction terms between these variables and others' punishment decision to investigate whether coordinated punishment is more or less prevalent for the different outcomes of the PGG stage of the game. We cluster standard errors at the individual level, correcting for repeated observations. $95 \%$ confidence interval in brackets and p-values in parentheses.

Dependent variable:

Punish (1 if yes, 0 otherwise)

(1)

(2)

(3)

\begin{tabular}{|c|c|c|c|}
\hline $\begin{array}{l}\text { Other punishes } \\
\text { (1 if yes, } 0 \text { if no) }\end{array}$ & $\begin{array}{c}0.547 \\
(0.005) \\
{[0.165-0.929]}\end{array}$ & $\begin{array}{c}0.272 \\
(0.032) \\
{[0.024-0.521]}\end{array}$ & $\begin{array}{c}0.382 \\
(<0.001) \\
{[0.169-0.594]}\end{array}$ \\
\hline $\begin{array}{l}\mathrm{CD} \\
\text { (1 if self cooperates and other defects, } 0 \\
\text { otherwise) }\end{array}$ & $\begin{array}{c}0.723 \\
(0.001) \\
{[0.291-1.155]}\end{array}$ & $\begin{array}{c}0.473 \\
(0.010) \\
{[0.112-0.834]}\end{array}$ & $\begin{array}{c}0.566 \\
(<0.001) \\
{[0.290-0.841]}\end{array}$ \\
\hline $\begin{array}{l}\mathrm{DC} \\
\text { (1 if self defects and other cooperates, } 0 \\
\text { otherwise) }\end{array}$ & $\begin{array}{c}-0.207 \\
(0.426) \\
{[-0.715-0.302]}\end{array}$ & $\begin{array}{c}-0.986 \\
(<0.001) \\
{[-1.474--0.498]}\end{array}$ & $\begin{array}{c}-0.632 \\
(<0.001) \\
{[-0.979--0.285]}\end{array}$ \\
\hline $\begin{array}{l}\mathrm{CC} \\
\text { (1 if self and other cooperates, } \\
0 \text { otherwise) }\end{array}$ & $\begin{array}{c}-0.758 \\
(0.014) \\
{[-1.363--0.152]}\end{array}$ & $\begin{array}{c}-1.271 \\
(<0.001) \\
{[-1.823--0.719]}\end{array}$ & $\begin{array}{c}-1.054 \\
(<0.001) \\
{[-1.459--0.648]}\end{array}$ \\
\hline Other punishes $\times \mathrm{CD}$ & $\begin{array}{c}-0.282 \\
(0.243) \\
{[-0.755-0.191]}\end{array}$ & $\begin{array}{c}-0.087 \\
(0.622) \\
{[-0.431-0.258]}\end{array}$ & $\begin{array}{c}-0.159 \\
(0.266) \\
{[-0.439-0.121]}\end{array}$ \\
\hline Other punishes $\times \mathrm{DC}$ & $\begin{array}{c}-0.133 \\
(0.654) \\
{[-0.714-0.448]}\end{array}$ & $\begin{array}{c}0.136 \\
(0.615) \\
{[-0.393-0.665]}\end{array}$ & $\begin{array}{c}0.029 \\
(0.883) \\
{[-0.355-0.412]}\end{array}$ \\
\hline Other punishes $\times \mathrm{CC}$ & $\begin{array}{c}-0.114 \\
(0.744) \\
{[-0.795-0.568]}\end{array}$ & $\begin{array}{c}-0.101 \\
(0.729) \\
{[-0.671-0.470]}\end{array}$ & $\begin{array}{c}-0.076 \\
(0.732) \\
{[-0.513-0.361]}\end{array}$ \\
\hline Constant & $\begin{array}{c}-2.143 \\
(<0.001) \\
{[-2.479--1.807]}\end{array}$ & $\begin{array}{c}-1.728 \\
(<0.001) \\
{[-1.987--1.468]}\end{array}$ & $\begin{array}{c}-1.899 \\
(<0.001) \\
{[-2.104--1.693]}\end{array}$ \\
\hline Number of observations & 2,672 & 3,088 & 5,760 \\
\hline Number of participants & 1,336 & 1,544 & 2,880 \\
\hline
\end{tabular}


Supplementary Table 3 | Responses to the extended questionnaire in the replication study. Numbers show mean [median] responses, separated by punishment types. Numbers in brackets are standard deviations.

\begin{tabular}{|c|c|c|c|c|}
\hline \multirow[b]{2}{*}{ Statement } & \multicolumn{4}{|c|}{ Agreement (1 = 'disagree strongly', 7 = 'agree strongly') } \\
\hline & $\begin{array}{l}\text { Non-punisher } \\
\text { (NP) }\end{array}$ & $\begin{array}{l}\text { Independent } \\
\text { punisher (IP) }\end{array}$ & $\begin{array}{l}\text { Coordinated } \\
\text { punisher } \\
\text { (CP) }\end{array}$ & $\begin{array}{l}\text { Anti-coordinated } \\
\text { punisher (ACP) }\end{array}$ \\
\hline $\begin{array}{l}\text { 1. When making my } \\
\text { decisions, I was unsure } \\
\text { what to do }\end{array}$ & $\begin{array}{l}3.2[3] \\
(1.8)\end{array}$ & $\begin{array}{l}3.7[4] \\
(1.7)\end{array}$ & $\begin{array}{c}4.0[4] \\
(1.6)\end{array}$ & $\begin{array}{c}4.4[5] \\
(1.6)\end{array}$ \\
\hline $\begin{array}{l}\text { 2. When making my } \\
\text { decisions, I was unsure } \\
\text { what was the appropriate } \\
\text { thing to do }\end{array}$ & $\begin{array}{l}3.2[3] \\
(1.8)\end{array}$ & $\begin{array}{c}3.8[4] \\
(1.8)\end{array}$ & $\begin{array}{c}4.2[4] \\
(1.5)\end{array}$ & $\begin{array}{c}4.5[5] \\
(1.6)\end{array}$ \\
\hline $\begin{array}{l}\text { 3. I did not want to let Blue } \\
\text { down in case they chose to } \\
\text { punish }\end{array}$ & $\begin{array}{c}3.9[4] \\
(1.8)\end{array}$ & $\begin{array}{l}4.5[5] \\
(1.6)\end{array}$ & $\begin{array}{c}4.9[5] \\
(1.5)\end{array}$ & $\begin{array}{c}4.5[4] \\
(1.4)\end{array}$ \\
\hline $\begin{array}{l}\text { 4. I wanted to reduce Red's } \\
\text { earnings myself }\end{array}$ & $\begin{array}{l}2.4[2] \\
(1.5)\end{array}$ & $\begin{array}{l}4.8[5] \\
(1.6)\end{array}$ & $\begin{array}{c}4.1[4] \\
(1.6)\end{array}$ & $\begin{array}{c}4.0[4] \\
(1.5)\end{array}$ \\
\hline $\begin{array}{l}\text { 5. I did not want to earn } \\
\text { less than Blue }\end{array}$ & $\begin{array}{c}4.3[4] \\
(1.6)\end{array}$ & $\begin{array}{c}4.6[5] \\
(1.7)\end{array}$ & $\begin{array}{c}4.9[5] \\
(1.2)\end{array}$ & $\begin{array}{c}4.5[4] \\
(1.4)\end{array}$ \\
\hline $\begin{array}{l}\text { 6. I did not want to reduce } \\
\text { my own earnings }\end{array}$ & $\begin{array}{c}6.3[7] \\
(1.1)\end{array}$ & $\begin{array}{l}5.4[5] \\
(1.5)\end{array}$ & $\begin{array}{l}5.9[6] \\
(1.0)\end{array}$ & $\begin{array}{c}5.6[6] \\
(1.4)\end{array}$ \\
\hline $\begin{array}{l}\text { 7. I did not want to reduce } \\
\text { Red's earnings by too } \\
\text { much }\end{array}$ & $\begin{array}{l}5.0[5] \\
(1.7)\end{array}$ & $\begin{array}{c}3.2[3] \\
(1.8)\end{array}$ & $\begin{array}{c}4.0[4] \\
(1.7)\end{array}$ & $\begin{array}{c}3.8[4] \\
(1.6)\end{array}$ \\
\hline
\end{tabular}


Supplementary Table 4 | Responses to the extended questionnaire in the replication study. Numbers shows mean [median] responses, separated by punishment types. Numbers in brackets are standard deviations.

\begin{tabular}{lcccc}
\hline & $\begin{array}{c}\text { Non-punisher } \\
(\mathrm{NP})\end{array}$ & $\begin{array}{c}\text { Independent } \\
\text { punisher (IP) }\end{array}$ & $\begin{array}{c}\text { Coordinated } \\
\text { punisher (CP) }\end{array}$ & $\begin{array}{c}\text { Anti-coordinated } \\
\text { punisher (ACP) }\end{array}$ \\
\hline \multirow{2}{*}{ Positive reciprocity } & $5.5[5.7]$ & $5.6[6.0]$ & $5.4[5.7]$ & $5.5[5.7]$ \\
& $(1.4)$ & $(1.5)$ & $(1.6)$ & $(1.0)$ \\
Negative reciprocity & $2.7[2.7]$ & $3.1[3.0]$ & $3.2[3.0]$ & $2.9[2.7]$ \\
& $(1.5)$ & $(1.7)$ & $(1.7)$ & $(1.4)$ \\
Risk & $5.9[6]$ & $6.6[7.0]$ & $6.7[7.0]$ & $6.6[7.0]$ \\
& $(2.4)$ & $(2.5)$ & $(2.4)$ & $(2.5)$ \\
Extraversion & $3.4[3.5]$ & $3.9[4.0]$ & $3.8[4.0]$ & $3.3[3.3]$ \\
& $(1.6)$ & $(1.7)$ & $(1.4)$ & $(1.3)$ \\
Agreeableness & $5.1[5.0]$ & $5.1[5.0]$ & $5.1[5.0]$ & $4.9[5.0]$ \\
& $(1.3)$ & $(1.4)$ & $(1.2)$ & $(1.3)$ \\
\hline \multirow{3}{*}{ Conscientiousness } & $5.4[5.5]$ & $5.5[5.5]$ & $5.2[5.5]$ & $5.2[5.5]$ \\
& $(1.2)$ & $(1.2)$ & $(1.3)$ & $(1.3)$ \\
\hline \multirow{2}{*}{ Emotional stability } & $4.7[5.0]$ & $4.9[5.0]$ & $4.5[4.5]$ & $4.6[4.5]$ \\
& $(1.6)$ & $(1.6)$ & $(1.4)$ & $(1.4)$ \\
\hline
\end{tabular}




\section{Supplementary Results}

\section{Effects of coordinated punishment on relative payoffs of cooperation and defection}

To explore how coordinated punishment could affect cooperation, we derive a simple model with the most common punishment preferences identified in our experiment. Our aim here is, with the help of some simplifying assumptions, to illustrate how the frequency of these punishment preferences in a population affects the relative payoffs of cooperation and defection. Note that we do not aim to explore how these punishment preferences may have emerged through evolutionary processes (e.g. through natural selection or social learning); we simply aim to explore the consequences for expected payoffs of cooperation and defection, under given relative frequencies of punishment preferences in the population.

Our experimental results indicate that the most common punishment preferences are: (1) to punish in the unconditional decision as well as in both conditional decisions (main text Figure 2c; red bar; let us denote this as punishment type $P$ ); and (2) to not-punish in the unconditional decision, and only punish conditional upon the other Punisher initialising punishment (in their unconditional punishment decision; main text Figure 2b; green bar; let us denote this as punishment type $Q$ ). We assume that individuals not belonging to either of these types ( $P$ or $Q$ ) do not punish at all.

For exploration purposes, we consider a population of infinite size, in which individuals are randomly matched to interact in groups of three. The structure of interactions is similar to our experiment. First, individuals interact in a binary Public Goods Game (PGG) in which they make a cooperation decision ('cooperate' or 'defect'). Subsequently, we randomly assign roles to the group members: two individuals will act a 'Punisher', and remaining one as the 'Target'. Punishers each make a binary decision whether or not to punish the Target. For our purposes, we first focus on punishment directed at Targets who defected in the PGG. At the end of this analysis we consider (anti-social) punishment towards cooperators.

As in the experiment, punishment takes place in two stages. (1) an 'unconditional' stage in which one of the Punishers observes the cooperation decision of the Target and independently chooses whether or not to punish them; (2) a 'conditional' stage in which the remaining punisher observes that unconditional punishment decision and decides whether or not to punish the Target. Punishment takes place according to the punisher's 'type'. For the sake of simplicity, we only focus on the impact of punishment on the relative expected payoffs of cooperation and defection, and ignore any costs that conducting punishment may impose on Punishers. 
To examine how coordinated punishment may affect the relative payoffs of cooperation and defection, we calculate how relative expected payoffs of these two decisions vary with the frequency of coordinated punishers in the population. In the PGG stage, all group members receive a benefit $b$ of the cooperation of all group members. Defectors avoid the cost $c$ of cooperating, so defection pays off better than cooperation. This 'cost of cooperation' can be offset if defectors receive punishment from their peers. Targets incur a cost $k$ for each peer that punishes them.

To compare the expected relative payoffs of cooperators and defectors, we need some notation. Let $p$ denote the fraction of individuals in the population who have punishment preference $P$ (see above), and punish both unconditionally and also in the conditional stage. Further, let $q$ denote the fraction of individuals in the population who have punishment preference $Q$, who do not punish unconditionally, but in the conditional stage only if the other Punisher has punished unconditionally. Individuals can have only one type of punishment preference, so $0 \leq p+q \leq 1$. We assume that the other $(1-p-q)$ do not punish. The expected payoffs for cooperation $\left(\pi_{C}\right)$ and for defection $\left(\pi_{D}\right)$ can be written as

$\pi_{C}=b-c$, and

$\pi_{D}=b-k \cdot[p \cdot(2+q)]$

The term between the square brackets is the expected number of individuals that punish a defector. It is calculated as follows. We first take the probability of unconditional punishment, which is simply equal to $p$, the frequency of punishment type $P$ in the population. Then we calculate the probability of conditional punishment. This punishment can be meted out by an individual of punishment type $P$ or $Q$ : this probability is given by the sum of $p$ (again, the frequency of $P$ who punish independently) plus the probability that unconditional punishment has taken place (again $p$ ) times $q$ (the frequency of coordinated punishers $Q$ ). We obtain the term between the square brackets by factoring out $p$ in $p+p+p \cdot q$.

To illustrate how coordinated punishers (type $Q$ ) affect the relative payoffs of cooperation and defection, we can derive a minimal frequency of type $P$ for which cooperation has higher expected payoffs than defection; that is $\pi_{C}>\pi_{\mathrm{D}}$.

$\pi_{C}>\pi_{\mathrm{D}}$ if $p>\frac{c}{k(2+q)}$

Supplementary Figure 3 shows that types that do not punish unconditionally, but will engage in coordinated punishment can substantially increase the range of conditions for which cooperation leads to higher expected payoffs than defection. In other words, for cooperation to thrive, a 
population requires a considerably lower frequency of individuals who punish free riding when there are individuals around who would not punish unconditionally, but who are ready to step in as soon as they observe punishment taking place.

These results are in line with a more detailed analysis showing that coordinated punishment can promote the evolutionary emergence of costly cooperation ${ }^{8}$. For simplicity, our analysis so far has only focused on punishment of defectors. Empirical evidence from a range of previous studies ${ }^{9-11}$ as well as observations from our experiment (cf Supplementary Figure 1) indicate that at times, punishment is aimed at cooperators. Such anti-social punishment can have strongly detrimental consequences for cooperation ${ }^{9,12-14}$. Moreover, if individuals tend to coordinate their punishment towards cooperators, coordinated punishment may no longer be able to promote cooperation ${ }^{15,16}$. In our model, anti-social punishment can be accounted for by writing the expected payoffs for cooperation and defection as:

$\pi_{C}=b-c-k \cdot\left[p^{\prime} \cdot(2+q)\right]$

$\pi_{D}=b-k \cdot[p \cdot(2+q)]$

where $p$ ' indicates the frequency of individuals who (anti-social) punish cooperators. Note that we assume that individuals with type $Q$, who coordinate their punishment, do not distinguish whether the target of punishment had defected or cooperated.

The conditions for cooperation to have higher expected payoffs than cooperation are then defined by:

$\pi_{C}>\pi_{\mathrm{D}}$ if $\left(p-p^{\prime}\right)>\frac{c}{k(2+q)}$

This shows that anti-social punishment decreases the scope for cooperation to thrive, and that in the context of this simple model, the relative expected payoffs of cooperation and defection reflect the frequency differences between pro-social $(p)$ and anti-social $\left(p^{\prime}\right)$ punishers. 


\section{Questionnaire targeted at motivations underlying punishment preferences}

Here we provide details on the extended questionnaire from the replication study probing possible motivations underlying conditional punishment preferences. To measure these motivations, participants in the role of Punisher were asked to think back to their decisions in the conditional punishment stage ( $c f$. Figure 1d,e of the main text). Then they had to use a 7-point scale to indicate their agreement with each of seven statements, where 1 means 'disagree strongly' and 7 means 'agree strongly'. Each of these statements was designed to measure a candidate motivation for punishment, and/or conditioning punishment on the punishment of others. (NB: remember that on the Punishers' experimental screens, the other Punisher was referred to as 'Blue' and the Target was referred to as 'Red'.)

The seven statements about the conditional punishment decisions were [with, in square brackets, the underlying motivation they aim to tap]:

1. When making my decisions, I was unsure what to do [requiring 'social proof ${ }^{\text {',2 }}$ ]

2. When making my decisions, I was unsure what was the appropriate thing to do [concerns for social appropriateness or legitimitacy ${ }^{3,4}$

3. I did not want to let Blue down in case they chose to punish [positive reciprocity towards the other Punisher]

4. I wanted to reduce Red's earnings myself [thirst for revenge]

5. I did not want to earn less than Blue [disadvantageous inequality aversion with regard to the other Punisher]

6. I did not want to reduce my own earnings [monetary concerns]

7. I did not want to reduce Red's earnings by too much [wanting to apply a fitting punishment (i.e. applying a sanction of proper magnitude)]

In the Supplementary Table 3, we show the mean and the median responses to these statements, broken down by conditional punishment type.

In the main text we focus on the different possible underlying motivations of those punishers who punish at least once in their conditional punishment decision, i.e., independent punisher (IP), coordinated punisher (CP), and anti-coordinated punisher (ACP). Here we complement these results by comparing these types with those who never punish, i.e., non-punishers (NP; Supplementary Table 3). Relatively speaking, non-punishers were less unsure about what to do (Mann Whitney U (MWU) test, $z=6.59$, d.f. $=1, P<0.001, r=0.17$ ) and less unsure about what the appropriate thing to do was (MWU test, $z=8.21$, d.f. $=1, P<0.001, r=0.21$ ). Furthermore, they were less concerned about letting the other punisher [Blue] down (MWU test, $z=6.93$, d.f. $=1, P<0.001, r=$ 
0.18 ) and they reported to be less driven by a thirst of revenge (MWU test, $z=16.67$, d.f. $=1, P<$ $0.001, r=0.42$ ). They further scored significantly higher on statements 6 (MWU test, $z=8.32$, d.f. $=1, P<0.001, r=0.21$ ) and 7 (MWU test, $z=11.68$, d.f. $=1, P<0.001, r=0.30$ ), indicating that concerns about their own and the target's earnings played an important role for not meting out any punishment.

In addition to these possible motivations underlying participants' behaviour in the particular punishment situation they encountered in our experiment, we also measured personality-level characteristics using established psychological scales. In particular, we administered a brief measurement of the big five personality scale ${ }^{5}$, gauged general dispositions towards positive and negative reciprocity ${ }^{6}$ and elicited risk preferences ${ }^{7}$.

Supplementary Table 4 shows mean [median] scores of these personality scales broken down by punishment type. While the different punishment types do not seem to differ with regard to dispositions towards positive reciprocity (Kruskal-Wallis $(\mathrm{KW})$ test, $\chi^{2}=6.03$, d.f. $=3, P=0.110$ ), we find them to differ with regard to their attitudes towards negative reciprocity $\left(\mathrm{KW}\right.$-test, $\chi^{2}=$ 12.48, d.f. $=3, P=0.006)$.

A closer inspection reveals that this effect is driven by non-punishers who display a significantly lower disposition towards negative reciprocity than any other type (MWU-test, $z=3.44$, d.f. $=1, P$ $<0.001, r=0.09$ ), while there is no pronounced difference among the remaining types (KW-test, $\chi^{2}$ $=0.83$, d.f. $=2, P=0.658$ ). A similar pattern can be observed with regard to risk attitudes. Nonpunishers are significantly less willing to take risks than the other three types (MWU-test, $z=4.71$, d.f. $=1, P<0.001, r=0.13)$, but there is no difference between the latter $\left(\mathrm{KW}\right.$-test, $\chi^{2}=0.03$, d.f. $=$ 2, $P=0.983, r=0.17)$.

With regard to the big five personality dimensions, the only notable difference across punishment types is with regard to extraversion $\left(\mathrm{KW}\right.$-test, $\chi^{2}=17.18$, d.f. $\left.=3, P<0.001\right)$. In particular, independent punisher and coordinated punisher score higher than non-punisher and anti-coordinated punisher (MWU-test, $z=3.79$, d.f. $=1, P<0.001, r=0.08$ ), with no difference between the former (MWU-test, $z=0.43$, d.f. $=1, P=0.666, r=0.01$ ) or the latter two (MWU-test, $z=0.46$, d.f. $=1, P$ $=0.648, r=0.03$ ). No significant differences are observed with regard to the other personality characteristics (KW-tests, all $P>0.173)$. 


\section{Supplementary Methods: Experimental materials}

Below we show on-screen instructions as displayed to participants. We start with the conditional punishment experiment. Then we show the follow-up experiment on conditional cooperation.

Participants could not navigate the experimental pages at will. Each time they pressed a button, the browser history was automatically overwritten. See Aréchar et al (2018) 'Conducting interactive experiments online ${ }^{17}$ for details.

NB: ' $==[$ notes $]==$ ' indicates a new screen, with occasional notes in brackets. Experimental code for both experiments are available upon request from the corresponding author.

\section{Conditional punishment experiment}

Differences between our main and the replication study are highlighted throughout, in purple. These differences were (i) addition of control questions prior to the punishment stages of the game; (ii) rewording of instructions to accommodate the counterbalanced design (so, half of the punishers made their 'conditional decision' before their 'unconditional decision); and (iii), addition of the questionnaires probing candidate motivation underlying conditional punishment preferences.

\section{Welcome!}

In this HIT you will be interacting with two other real MTurkers who also accepted this HIT, and who are participating at the same time as you. It is therefore important that you complete this HIT without interruptions. Including the time to read these instructions, the HIT will take about 8 minutes to complete.

During this HIT you can earn Points. The number of Points you earn depends on your decisions and the decisions of the other participants. You receive 4 Points to start with. At the end of the HIT your Points will be converted into real money $(\mathbf{1 0}$ Points $=\mathbf{\$ 1 , 0 0})$. In addition, you will receive $\$ 0.50$ on top of however much you earn during the HIT. You will receive a code to enter into MTurk to collect your payment once you have finished.

Please click the link below to start the HIT.

[continue]

$==[$ instructions for Stage $1($ cf. main text Figure 1a) $]==$

\section{Your task}

At the beginning of the HIT you and two other real MTurkers will form a group. We will refer to the other members of your group simply as Other $\mathbf{1}$ and Other 2. 
In your group, you will make decisions in two Stages which can affect your earnings.

\section{Stage I}

In Stage I you and the two other participants each will choose between two options: Options $\mathbf{X}$ and Y. Your choice can affect your own earnings and the earnings of the other two participants. The earnings (in Points) of Options $\mathrm{X}$ and $\mathrm{Y}$ for each of the participants are:
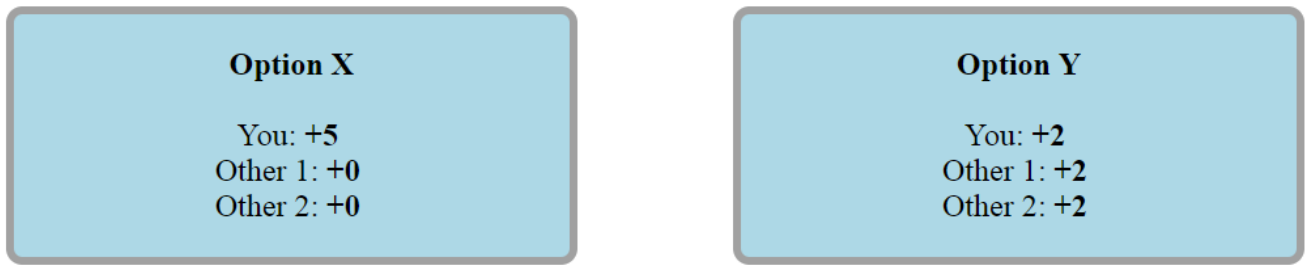

The following table illustrates how the possible outcomes of Stage I depend on yourself and the two other participants:

\begin{tabular}{|c|c|c|}
\hline If you choose... & $\begin{array}{c}\text { and the two other } \\
\text { participants choose... }\end{array}$ & $\begin{array}{c}\text { then your earnings } \\
\text { are: }\end{array}$ \\
\hline $\mathbf{X}$ & $\mathbf{X}$ and $\mathbf{X}$ & 5 \\
\hline $\mathbf{X}$ & $\mathbf{X}$ and $\mathbf{Y}$ & 7 \\
\hline $\mathbf{X}$ & $\mathbf{Y}$ and $\mathbf{Y}$ & 9 \\
\hline $\mathbf{Y}$ & $\mathbf{X}$ and $\mathbf{X}$ & 2 \\
\hline $\mathbf{Y}$ & $\mathbf{X}$ and $\mathbf{Y}$ & 4 \\
\hline $\mathbf{Y}$ & $\mathbf{Y}$ and $\mathbf{Y}$ & 6 \\
\hline
\end{tabular}

Important: All group members make their choice between Option X and Option $\mathrm{Y}$ at the same time. Once both you and the other two participants have made a decision, you proceed to Stage II.

\section{Stage II}

Before the beginning of Stage II, every group member is randomly assigned a color label. Two group members will be labeled Blue and one will be labeled Red. If you are assigned Red, you do not have to make a decision in Stage II.

If you are assigned Blue, you will be informed about Red's decision in Stage I. Then you will choose between Options P and Q. Your choice can only affect Red and yourself. The earnings (in Points) of Options P and Q for you and Red are: 


\section{Option P}

You: $\mathbf{- 1}$

Red: $-\mathbf{3}$
Option Q

You: $+\mathbf{0}$

Red: + 0

Remember: in this HIT you will be interacting with real other MTurkers who are completing this HIT at the same time. Please observe the time limit shown on your screen to avoid long waiting times. If you fail to respond in time, you will be excluded from the task and we will not be able to pay you.

Please click below if you understood your task. The link will open in a new window, so that you can always refer back to these instructions.

[I have read the instructions and I understood my task. Continue]

$==[$ Compulsory comprehension questions. Participants could only proceed once they have all questions correctly] $==$

\section{Control questions}

Please answer the following questions to check your understanding of the decision situation.

Question 1: Suppose that all three group members (including you) choose Option Y.

a. How many Points will you earn in Stage I?

b. How many Points will each of the other two group members earn in Stage I?

Question 2: Suppose that all three group members (including you) choose Option $\mathbf{X}$.

a. How many Points will you earn in Stage I?

b. How many Points will each of the other two group members earn in Stage I?

Question 3: Suppose that the other two group members chose Option Y.

a. How many Points will you earn in Stage I if you would choose Option Y?

b. How many Points will you earn in Stage I if you would choose Option X?

[submit]

$==[$ A 'lobby' page, where participants waited to be matched with others. In the below screen, the ' $\mathrm{X}$ ' was updated as other participants entered the lobby. Once 3 participants were in the lobby, they were automatically matched and directed to the next page. The countdown timer is initially set to 2 minutes. If this timer reaches 0 , participants are given the option to leave the HIT and collect their participation fee, or to return to the lobby and wait for an additional 2 minutes] $==$ 
Please wait until the other members of your group are ready.

We are currently waiting for $X$ participants.

If you are still waiting when the time below is up,

you can leave this HIT and collect your participation fee.

[[countdown timer]]

$==[$ Public Goods Game decision. Countdown timer set to 30 seconds. $]==$

\section{Stage I}

You have been grouped with two other participants, Other 1 and Other 2.

Please select your choice and submit.

[[countdown timer $]]$
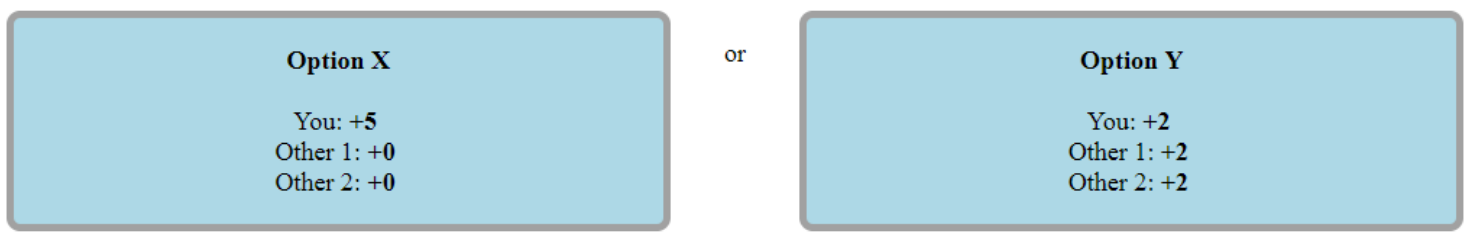

[submit]

$==$ [Instructions Stage 2. Instructions for Punishers (Target in italics); From this page, Targets are directed to a waiting screen and could only proceed once the two Punishers had made their decisions.] $==$

\section{Beginning of Stage II}

All members of your group have made their decision for Stage I. Stage II will start now.

The computer program has randomly assigned color labels to each of the members of your group. Two group members received a blue label, and one received a red label.

You have been assigned a blue label. [You have been assigned a red label]

This means that you do [not] have to make a decision in Stage II. After Stage II all group members will be informed about all decisions and their final earnings in both Stages.

Please click below to continue. 
$==[$ The following pages were specific to Punishers (Blue players); Targets (Red player) were directed to the questionnaire. As soon as the Blue players in their group had made their punishment decisions, they proceeded to the results screen (see below) ] ==

\section{Stage II (punishers only)}

You and one other group member were assigned the blue label. We will refer to this other group member simply as Blue. Similarly, we will refer to the group member with the red label as Red.

In this Stage, both you and Blue will make two types of decisions. You will make these decisions in two Steps: Step 1 and Step 2.

$===$ [in the replication experiment, the last two sentences were changed to accommodate the counterbalanced design. In particular, we avoided introducing 'Step 1' and 'Step 2' and then say for half the participants that they had to make their Step 2 decision first. So, this sentence read: "(...) both you and Blue will make two types of decisions: as first mover and as second mover. "] ===

To begin with, you will be informed about the decision of Red in Stage I.

In Step 1 [replication experiment: as first mover] you will choose between Option $\mathbf{P}$ and Option Q. The earnings (in Points) of Options P and Q for you and Red are:
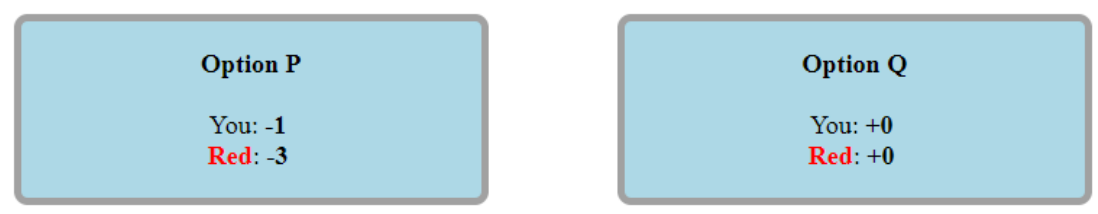

Blue will make this decision at the same time.

In Step 2 you will again choose between Option $\mathbf{P}$ and Option $\mathbf{Q}$. However, now you can make your decision dependent on what Blue decided in Step 1. This means that we will ask you:

- What would you choose if in Step 1 Blue chose Option P? [replication experiment: "What would you choose if Blue chose Option P as first mover?']

- What would you choose if in Step 1 Blue chose Option Q? [replication experiment: "What would you choose if Blue chose Option Q as first mover?"]

[replication experiment only, for original (reversed) decision order: "You will start with making your first (second) mover decision, followed by your second (first) mover decision.”]

Once both you and Blue have completed Step 1 and Step 2, the computer program randomly selects either you or Blue as the first mover. The remaining participant will be the second mover. 
[replication experiment: "Once you and Blue have completed your first mover and second mover decisions, the computer program randomly determines which decisions will be applied. This means that the computer selects either you or Blue as the first mover The remaining participant will be the second mover."]

The following table illustrates how the outcome of Stage II depends on the choices of the first and the second mover:

\begin{tabular}{|c|c|c|c|c|c|}
\hline $\begin{array}{c}\text { If the first } \\
\text { mover } \\
\text { chooses... }\end{array}$ & $\begin{array}{c}\text { and the } \\
\text { corresponding } \\
\text { choice of the } \\
\text { second mover is... }\end{array}$ & $\begin{array}{c}\text { then the } \\
\text { earnings } \\
\text { in Stage II } \\
\text { are: }\end{array}$ & $\begin{array}{c}\text { first } \\
\text { mover: }\end{array}$ & $\begin{array}{c}\text { second } \\
\text { mover: }\end{array}$ & Red \\
\hline P & P & & -1 & -1 & -6 \\
\hline P & Q & & -1 & 0 & -3 \\
\hline $\mathbf{Q}$ & P & & 0 & -1 & -3 \\
\hline $\mathbf{Q}$ & $\mathbf{Q}$ & & 0 & 0 & 0 \\
\hline
\end{tabular}

After Stage II all group members will be informed about all decisions and their final earnings for both Stages.

Please click below if you understood your task.

$===[$ Compulsory comprehension questions. Participants could only proceed once they have all questions correctly; only shown to punishers in replication experiment] $===$ 


\section{Control questions}

Please answer the following questions to check your understanding of the decision situation

Question 1: Suppose that the computer program selects you as the first mover.

a. How many Points will you earn in Stage II if you selected $\mathbf{P}$ for that case?

b. How many Points will you earn in Stage II if you selected $\mathbf{Q}$ for that case?

Question 2: Suppose that the computer program selects you as the second mover. Suppose that Blue chose $\mathbf{P}$ as first mover.

a. How many Points will you earn in Stage II if you selected $\mathbf{P}$ for that case?

b. How many Points will Blue earn in Stage II if you selected $\mathbf{P}$ for that case?

c. How many Points will Red earn in Stage II if you selected $\mathbf{P}$ for that case?

[Continue]

[Back to instructions]

$==[$ The unconditional punishment decision; cf. main text Figure 1c; countdown timer set to 60 seconds] $==$

Step 1 (punishers only) [Replication experiment: "Your first mover decision"]

[[countdown timer]]

In Stage I, Red chose Option X.

The earnings (in Points) from this choice are:

You: +0, Blue: +0, Red: +5 .

Please select your choice and submit.

Option P

You: -1

Red: $\mathbf{- 3}$
Option Q

You: $+\mathbf{0}$

Red: +0 
[submit]

$==[$ The conditional punishment decisions; both on the same screen; cf. main text Figure 1d and e; countdown timer set to 60 seconds]] ==

Step 2 (punishers only) [Replication experiment: "Your second mover decision"]

[[countdown timer $]]$

In Stage I, Red chose Option X.

The earnings (in Points) from this choice are:

You: $+\mathbf{0}$, Blue: $+\mathbf{0}$, Red: +5 .

What would you choose if in Step 1 Blue chose Option P?
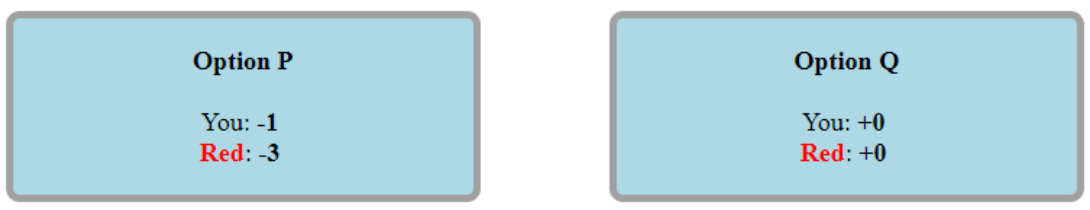

What would you choose if in Step 1 Blue chose Option Q?
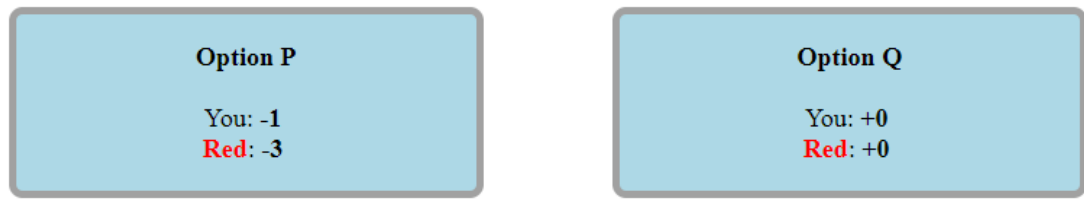

[submit]

$==$ [Decision phase of the experiment is over. Questionnaire items follow; anger was elicited in both the original study and the replication study] $===$

\section{Questionnaire (punishers only)}

In Stage I, Red chose Option Y.

Your earnings from Red's choice: $+\mathbf{0}$.

How angry did you feel when you found out Red decision in Stage I?

Not angry at all $\quad 0000000000$ Very angry 
$===$ [Questionnaire eliciting possible motivations underlying the observed punishment preferences; cf. Supplementary Results B; only shown in replication study] ===

\section{Questionnaire}

Now please think back of Stage II of the game you just played.

In that Stage you chose between Option $\mathbf{P}$ and Option $\mathbf{Q}$.

The earnings (in Points) of Options $\mathbf{P}$ and $\mathbf{Q}$ for you and Red were:
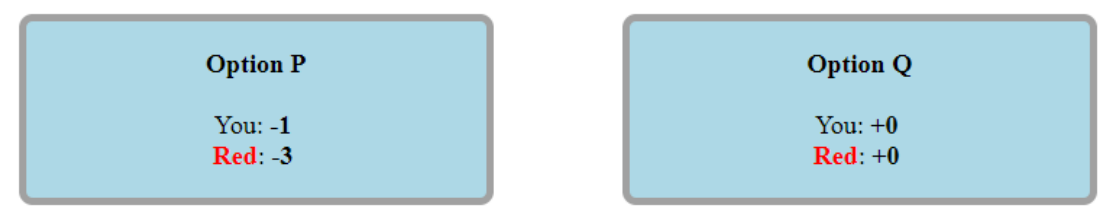

You made this decision in two situations:

(1) in case Blue chose Option $\mathbf{P}$, you chose [XXX]

(2) in case Blue chose Option $\mathbf{Q}$, you chose [XXX]

Below we list seven statements about your decisions in this Stage.

Please indicate for each to which extent you agree with the statement.

$==$ [For each of the following questions, participants had to choose one of the following answers: 'Disagree strongly', 'Disagree moderately', 'Disagree a little', 'Neither agree nor disagree', 'Agree a little', 'Agree moderately', 'Agree strongly']

1. When making my decision, I was unsure what to do.

2. When making my decision, I was unsure what one should do.

3. I did not want to earn less than Blue.

4. I did not want let Blue down in case they chose P.

5. I did not want to reduce Red's earnings by too much.

6. I wanted to reduce Red's earnings myself.

7. I did not want to reduce my own earnings.

$===$ [Elicitation of Big Five Personality traits (based on Gosling et al., 2003); only shown in replication study] $===$

This part of the questionnaire is about yourself.

Below we list ten brief statements.

Please indicate for each to which extent you agree with the statement.

$==$ [For each of the following questions, participants had to choose one of the following answers: 'Disagree strongly', 'Disagree moderately', 'Disagree a little', 'Neither agree nor disagree', 'Agree a little', 'Agree moderately', 'Agree strongly'] 
I see myself as...

... Extraverted, enthusiastic

... Critical, quarrelsome

... Dependable, self-disciplines

... Anxious, easily upset

... Open to new experiences, complex

... Reserved, quiet

... Sympathetic, warm

... Disorganized, careless

... Calm, emotionally stable

... Conventional, uncreative

$===[$ Elicitation of attitudes towards positive and negative reciprocity (based on Perugini et al., 2003); only shown in replication study] ===

Below we list some brief statements about yourself.

Please indicate for each to which extent you agree with the statement.

$==$ [For each of the following questions, participants had to choose one of the following answers: 'Disagree strongly', 'Disagree moderately', 'Disagree a little', 'Neither agree nor disagree', 'Agree a little', 'Agree moderately', 'Agree strongly']

If someone does me a favour, I am prepared to return it.

If I suffer a serious wrong, I will take revenge as soon as possible, no matter what the cost.

If somebody puts me in a difficult position, I will do the same to him/her.

I go out of my way to help somebody who has been kind to me before.

If somebody offends me, I will offend him/her back.

I am ready to incur personal costs to help somebody who helped me before

$===$ [Elicitation of risk attitudes (based on Dohmen et al., 2011); only shown in replication study ]$===$

How do you see yourself: Are you generally a person who is fully prepared to take risks or do you try to avoid taking risk?

$==$ [For this questions, participants had to choose on a 10 item Likert scale where 1 means: 'avoid risks' and 10 means 'fully prepared to take risks']

$===[$ Final questionnaire screen shown to all participants $]===$

\section{Questionnaire}

What is your gender? 
What is your age?

$==[$ Results screen listing the outcome of the first and the second stage of the game $]==$

\section{Results}

Stage I

You chose Option $\mathbf{X}$.

One Blue chose Option Y.

The other Blue chose Option Y.

Your earnings from Stage I: 9 Points.

\section{Stage II}

The decisions of the two Blue participants were:

Option $\mathbf{P}$ and Option $\mathbf{P}$.

Your earnings from Stage II: -6 Points.

You started with 4 Points.

So, in total you have earned 7 Points.

$==[$ Final earnings screen; the 'unique code' was specific to each participant and allowed us to pay out bonus earnings based on decisions in the game] $==$

\section{Your earnings}

In this experiment you earned XXX Points.

These Points are worth $\$ X X X$. This is your bonus for this HIT.

The guaranteed participation fee for completing this HIT is $\$ 0.50$.

So, in total you will receive \$XXX.

Note that your participation fee and your bonus will be paid separately.

Thank you very much for your participation!

To receive your payment please copy the following unique code and enter it into MTurk:

[10-digit code specific to each participant to match earnings between our records and MTurk]

After entering your code you can close this window. 


\section{Conditional cooperation experiment}

Below we show the instructions for the follow-up experiment in which we elicited participants' preferences for conditional cooperation.

\section{Instructions}

Thank you for accepting this HIT. In this HIT you will be interacting with another real MTurker who also accepted this HIT. Including the time to read these instructions, the HIT will take about 5 minutes to complete.

During this HIT you can earn Points. The number of Points you earn depends on your decisions and the decisions of the other MTurker. At the end of the HIT your Points will be converted into real money (5 Points $=\$ \mathbf{1 . 0 0}$ ). In addition, you will receive $\$ 0.50$ on top of however much you earn during the HIT. You will receive a code to enter into MTurk to collect your payment once you have finished.

Please click the link below to start the HIT.

\section{Your Task}

In this HIT you and the other real MTurker will form a group. You and the other participant will make two types of decisions. You will make these decisions in two Steps: Step 1 and Step 2.

In Step 1 you will choose between Option $\mathbf{X}$ and Option $\mathbf{Y}$. The earnings (in Points) of Options X and Y for you and the other participant are:

\begin{tabular}{|c|c|}
\hline Option $\mathrm{X}$ & Option $\mathrm{Y}$ \\
& \\
You: $+\mathbf{3}$ & You: $\mathbf{+ 2}$ \\
They: $+\mathbf{0}$ & They: $+\mathbf{2}$ \\
\hline
\end{tabular}

They will make the same decision.

In Step 2 you will again choose between Option $\mathbf{X}$ and Option $\mathbf{Y}$. However, now you can make your decision dependent on what they decided in Step 1. This means that we will ask you:

- What would you choose if in Step 1 they chose Option X?

- What would you choose if in Step 1 they chose Option Y?

\section{Determining Outcomes}

Once both you and the other participant have completed Step 1 and Step 2, the computer program randomly 
selects either you or the other participant as the first mover. The remaining participant will be the second mover.

The following table illustrates how the outcome depends on the first mover's and the second mover's choice:

\begin{tabular}{|c|c|c|c|}
\hline $\begin{array}{c}\text { If the first } \\
\text { mover in Step } \\
1 \text { chooses... }\end{array}$ & $\begin{array}{c}\text { and the } \\
\text { corresponding } \\
\text { choice of the second } \\
\text { mover in Step 2 is... }\end{array}$ & $\begin{array}{c}\text { then the } \\
\text { first } \\
\text { mover's } \\
\text { earnings } \\
\text { are }\end{array}$ & $\begin{array}{c}\text { and the } \\
\text { second } \\
\text { mover's } \\
\text { earnings } \\
\text { are }\end{array}$ \\
\hline $\mathrm{X}$ & $\mathrm{X}$ & 3 & 3 \\
\hline $\mathrm{X}$ & $\mathrm{Y}$ & 5 & 2 \\
\hline $\mathrm{Y}$ & $\mathrm{X}$ & 2 & 5 \\
\hline $\mathrm{Y}$ & $\mathrm{Y}$ & 4 & 4 \\
\hline
\end{tabular}

Please click below if you understood your task.

\section{Control questions}

Please answer the following questions to check your understanding of the decision situation.

Recall the two options:

\begin{tabular}{|c|c|}
\hline Option $\mathrm{X}$ & Option $\mathrm{Y}$ \\
& \\
You: $+\mathbf{+ 3}$ & You: $+\mathbf{2}$ \\
They: $+\mathbf{0}$ & They: $+\mathbf{2}$ \\
\hline
\end{tabular}


Question 1: Suppose that you and the other participant both choose Option X.

a. How many Points will you earn?

b. How many Points will the other participant earn?

Question 2: Suppose that you and the other participant both choose Option Y. a. How many Points will you earn?

a. How many Points will you earn?

b. How many Points will the other participant earn?

Question 3: Suppose that the other participant chooses Option Y.

a. How many Points will you earn if you would choose Option Y

b. How many Points will you earn if you would choose Option $\mathbf{X}$ ?

\section{Step 1}

Please make a choice between the following two options:

\begin{tabular}{|c|c|}
\hline Option $\mathrm{X}$ & Option $\mathrm{Y}$ \\
& \\
You: $+\mathbf{3}$ & You: $+\mathbf{2}$ \\
They: $+\mathbf{0}$ & They: $+\mathbf{2}$ \\
\hline
\end{tabular}

I choose

\section{Option X}

Option Y

\section{Step 2}

Recall the two choice options: 


\begin{tabular}{|c|c|}
\hline Option $\mathbf{X}$ & Option $\mathbf{Y}$ \\
& \\
You: $+\mathbf{3}$ & You: $\mathbf{+ 2}$ \\
They: $+\mathbf{0}$ & They: $+\mathbf{2}$ \\
\hline
\end{tabular}

What would you choose if in Step 1 they chose Option $\mathbf{X}$ ?

\section{Option X}

\section{Option Y}

What would you choose if in Step 1 they chose Option Y?

\section{Option X}

\section{Option Y}

\section{Your bonus earnings}

Your bonus earnings for this HIT will be determined as follows. On DD-MM-YYYY, the decisions of all MTurkers who have participated in this HIT will be collected, and you will be randomly matched with another participant.

As explained before, a computer program will randomly select either you or the other participant as the first mover. The remaining participant will be the second mover. Your earnings will be calculated by implementing the first mover's decision in Step I, and the corresponding decision of the second mover in Step II.

Please note that your guaranteed participation fee of $\$ 0.50$ and your bonus will be paid separately.

Please click below to continue and receive your completion code to input on MTurk. 


\section{Supplementary References}

1. Cialdini, R. B. \& Trost, M. R. Social influence: Social norms, conformity and compliance. in The handbook of social psychology, Vols. 1 and 2 (4th ed.) (eds. Gilbert, D. T., Fiske, S. T. \& Lindzey, G.) 151-192 (McGraw-Hill, 1998).

2. Cialdini, R. B. \& Cialdini, R. B. Influence: The psychology of persuasion. (Collins New York, 2007).

3. Boehm, C. Hierarchy in the forest: Egalitarianism and the evolution of human altruism. (Harvard University Press.[aDSW], 1999).

4. Wiessner, P. Norm enforcement among the Ju/'hoansi Bushmen. Hum. Nat. 16, 115-145 (2005).

5. Gosling, S. D., Rentfrow, P. J. \& Swann, W. B. A very brief measure of the Big-Five personality domains. J. Res. Personal. 37, 504-528 (2003).

6. Perugini, M., Gallucci, M., Presaghi, F. \& Ercolani, A. P. The personal norm of reciprocity. Eur. J. Personal. 17, 251-283 (2003).

7. Dohmen, T. et al. Individual risk attitudes: Measurement, determinants, and behavioral consequences. J. Eur. Econ. Assoc. 9, 522-550 (2011).

8. Boyd, R., Gintis, H. \& Bowles, S. Coordinated punishment of defectors sustains cooperation and can proliferate when rare. Science 328, 617-620 (2010).

9. Herrmann, B., Thöni, C. \& Gächter, S. Antisocial punishment across societies. Science 319, 1362-1367 (2008).

10. Nikiforakis, N. Punishment and counter-punishment in public good games: Can we really govern ourselves? J. Public Econ. 92, 91-112 (2008).

11. Gächter, S., Herrmann, B. \& Thöni, C. Culture and cooperation. Philos. Trans. R. Soc. B Biol. Sci. 365, 2651-2661 (2010).

12. Rand, D. G. \& Nowak, M. A. The evolution of antisocial punishment in optional public goods games. Nat. Commun. 2, 434 (2011).

13. García, J. \& Traulsen, A. Leaving the loners alone: Evolution of cooperation in the presence of antisocial punishment. J. Theor. Biol. 307, 168-173 (2012).

14. Hauser, O. P., Nowak, M. A. \& Rand, D. G. Punishment does not promote cooperation under exploration dynamics when anti-social punishment is possible. J. Theor. Biol. 360, 163-171 (2014).

15. McCabe, C. M. \& Rand, D. G. Coordinated punishment does not proliferate when defectors can also punish cooperators. J. Commun. Res. 6, (2014).

16. Huang, F., Chen, X. \& Wang, L. Conditional punishment is a double-edged sword in promoting cooperation. Sci. Rep. 8, 528 (2018).

17. Arechar, A. A., Gächter, S. \& Molleman, L. Conducting interactive experiments online. Exp. Econ. 21, 99-131 (2018). 